\title{
¿Hay algo que los planes puedan hacer por la teoría del derecho?*
}

\author{
What Can Plans Do for Legal Theory?
}

Bruno Celano**

We're only making planes for Nigel...

Recepción y evaluación de propuesta: 24/10/2017

Aceptación: 26/02/2018

Recepción y aceptación final: 16/08/2018

\begin{abstract}
Resumen: En su libro, Legalidad, Scott Shapiro afirma ofrecer una respuesta, "nueva que, con suerte, será mejor" (es decir, mejor de las que han sido ofrecidas hasta el momento), a la pregunta fundamental '¿qué es el derecho?'. La tesis central de esta nueva explicación -la tesis de los planes- es que la actividad jurídica es una forma de planificación social: "Las instituciones jurídicas planifican para las comunidades sobre las que pretenden tener autoridad, tanto diciendo a sus miembros qué pueden, o no pueden, hacer, como identificando quiénes tienen derecho a afectar lo que otros pueden o no hacer". La noción relevante de planes es la noción moldeada, en la filosofía de la acción, por Bratman. Según Shapiro, este enfoque hace posible un progreso sustancial en la teoría del derecho. ¿Qué pueden hacer los planes (bratmanianos)
\end{abstract}

Traducción de Federico José Arena.

** Profesor de Filosofía del Derecho en la Università degli Studi di Palermo, Italia. E-mail: celano@unipa.it; www.unipa.it/celano. Una versión previa de este trabajo fue presentada en el workshop "The Planning Theory of law. A Workshop with Scott Shapiro" (Università Bocconi, Milán, 10 y 11 de diciembre de 2009). Quisiera agradecer a todos los participantes en ese workshop, como también a Scott Shapiro, por la valiosa discusión. 
para la teoría del derecho? ¿Recurrir al concepto de plan de Bratman, tal como propone hacerlo Shapiro, brinda efectivamente una nueva y especial visión de la naturaleza del derecho? Mi argumento es que la respuesta es negativa.

Palabras clave: Bratman, filosofía de la acción, Shapiro, tesis de los planes.

\begin{abstract}
In his book, Legalidad, Scott Shapiro puts forward what he claims to be "a new, and hopefully better" (better, namely, than the ones given so far) answer to "the overarching question of "What is law?". The central claim of this new account - the "Planning Thesis" - is that "legal activity is a form of social planning". "Legal institutions plan for the communities over which they claim authority, both by telling members what they may or may not do and by identifying those who are entitled to affect what others may or may not do. The relevant notion of a plan is the notion moulded, in the philosophy of action, by M. E. Bratman. According to Shapiro, this approach makes substantial progress in legal theory possible. What, then, can (Bratmanian) plans do for legal theory? Does resort to Bratman's concept of a plan - along the lines followed by Shapiro - in fact provide new and special insight into the nature of law? I argue that the answer is negative.
\end{abstract}

Keywords: Bratman, philosophy of action, planning thesis, Shapiro.

\title{
I. Introducción
}

En su libro, Legalidad ${ }^{1}$, Scott Shapiro afirma ofrecer una respuesta, "nueva que, con suerte, será mejor" (es decir, mejor de las que han sido ofrecidas hasta el momento), a "la pregunta fundamental '¿qué es el derecho?"', es decir, una explicación de "la naturaleza fundamental del derecho"3. La tesis central de esta nueva explicación es que "las reglas fundamentales de los sistemas jurídicos son planes. Su función es estructurar la actividad jurídica, de manera que los participantes

1 Shapiro, S. J., Legalidad, Madrid-Barcelona, Marcial Pons, 2014.

Ibidem, p. 28. 
¿Hay algo que los planes puedan hacer por la teoría del derecho?

puedan trabajar juntos y así lograr bienes y realizar valores que de otra forma serían inalcanzables"4.

Shapiro agrega que la idea central del libro - la "Tesis de los planes"- es que la actividad jurídica es una forma de planificación social ${ }^{5}$ (la actividad jurídica es definida como "el ejercicio de la autoridad jurídica"6):

Las instituciones jurídicas planifican para las comunidades sobre las que pretenden tener autoridad, tanto diciendo a sus miembros qué pueden, o no pueden, hacer, como identificando quiénes tienen derecho a afectar lo que otros pueden o no hacer. Siguiendo esta idea, las reglas jurídicas son ellas mismas planes generalizados, o normas similares a los planes, emitidas por quienes están autorizados a planificar para otros. Y la decisión judicial supone la aplicación de estos planes, o normas similares a los planes, a quienes les son aplicables. Así, el derecho organiza el comportamiento individual y colectivo para que los miembros de la comunidad puedan alcanzar bienes morales que, de otro modo, no se hubiesen conseguido, o no se hubiesen conseguido tan bien ${ }^{7}$.

Shapiro sostiene que la teoría del derecho como plan ofrece una solución para algunas de las paradojas que durante mucho tiempo han aquejado a la teoría del derecho. Más específicamente, ofrece una solución a la paradoja de la autoridad (¿cómo es posible la autoridad del derecho?) y permite también superar el desafío de Hume (usted no puede derivar un "deber" de un "es"). Además, la teoría hace todo ello defendiendo la concepción positivista del derecho, frente a las principales objeciones dirigidas contra sus versiones más influyentes (i.e., la de Austin y la de Hart). Asimismo, según Shapiro, las respuestas (como la teoría de los planes) a la pregunta sobre la naturaleza del derecho con-

4 Ibidem, p. 160, he omitido las cursivas.

5 Ibidem, p. 200.

6 Ibidem, p. 245.

7 Ibidem, pp. 200-201. 
tribuyen también a responder las preguntas relativas a qué es el derecho en situaciones particulares, puesto que dan fundamento a afirmaciones sobre la autoridad del derecho y contribuyen a establecer cuáles son los métodos interpretativos apropiados en una determinada jurisdicción ${ }^{8}$. (Las respuestas a la pregunta por la naturaleza del derecho producen una diferencia práctica, puesto que contribuyen a determinar cuáles hechos jurídicos se verifican y, por lo tanto, permiten determinar la verdad o falsedad de las proposiciones de derecho).

Todo esto se logra, básicamente, recurriendo al concepto de plan, y a la idea central según la cual los seres humanos son agentes que planifican. Ciertamente, el término "plan", en sí mismo, no dice mucho (y lo mismo puede decirse de la expresión "agentes que planifican"). La noción relevante de plan es la noción elaborada, en sus trabajos sobre filosofía de la acción, por Bratman. Así, cuando Shapiro afirma que los humanos son agentes que planifican, debe entenderse como una referencia a la teoría de la agencia como planificación desarrollada por Bratman. Es precisamente mediante este recurso al concepto de plan, $y$ al modo en que Bratman entiende la agencia humana como planificación, que es posible, según Shapiro, producir un avance sustancial en teoría del derecho, en los términos sugeridos más arriba.

Preguntémonos, entonces, ¿qué pueden hacer los planes (bratmanianos) por la teoría del derecho? ¿Recurrir al concepto de plan elaborado por Bratman nos permite efectivamente construir un enfoque nuevo y especial de la naturaleza del derecho? ¿La tesis de la planificación -entendida (como se debe) según las líneas de Bratman- nos dice, en efecto, algo especialmente informativo acerca de qué es el derecho y qué son las normas jurídicas? La pregunta es, de hecho, doble. Primero, ¿el aparato conceptual, la sintaxis teórica y la terminología de la teoría de la agencia como planificación de Bratman nos permite descubrir y formular algunas verdades importantes acerca de la naturaleza del derecho, verdades que no habría sido posible formular, usando la terminología ordinaria de las normas, reglas, principios, o incluso, quizás, de las órdenes, amenazas, obediencia o aquiescencia? Segundo, ¿la noción 
¿Hay algo que los planes puedan hacer por la teoría del derecho?

de plan de Bratman puede efectivamente desempeñar la función que Shapiro le atribuye? En otras palabras, ¿pueden las normas jurídicas (o quizás solo las normas jurídicas "fundamentales") ser legítimamente caracterizadas como planes (bratmanianos)? Tengo dudas respecto de ambas preguntas ${ }^{9}$.

\section{Planificar en tercera persona}

Los planes -por supuesto, bratmanianos (este adjetivo será evitado en lo que sigue)- son creados y adoptados por un agente respecto de $s u$ propia acción y deliberación futuras. Son un dispositivo relativo a la autogestión de los agentes. ¿Es de ayuda pensar al derecho a partir del modelo de la autogestión?

¿De todos modos, por qué hablar de "autogestión"? Esto no es del todo correcto. Bratman es claro como el agua cuando afirma que los planes para la autogestión son un tipo especial de planes. Típicamente son un tipo especial de políticas, relativas a qué ha de ser tratado como una razón, y que se encuentran en una relación jerárquica respecto de las actitudes de primer orden ${ }^{10}$.

El punto, sin embargo, es que los planes se refieren a las propias acciones y actitudes del agente. Y, según Shapiro, el derecho debe ser entendido como un conjunto de planes referidos también, y sobre todo, a las acciones y deliberaciones de otras personas y no solo de quien planifica. Las normas jurídicas son, típicamente, planes creados y adoptados (también y principalmente) para otros.

Ciertamente es posible, en algún sentido, hacer planes para otros. Me parece, sin embargo, que planificar es un fenómeno interesante e iluminador cuando es concebido como un aspecto de la acción en

9 Bratman es bastante favorable al matrimonio entre sus propios puntos de vista y la teoría del derecho; y, en sus trabajos más recientes, reconoce a Shapiro el haberle hecho sugerencias y lúcidos comentarios sobre esa y otras cuestiones. Lo que me pregunto es cuán sólido puede ser ese matrimonio.

10 Bratman, M. E., Structures of Agency. Essays, Oxford, Oxford University Press, 2007, capítulos 1, 2, 7-10. 
primera persona (singular o plural, véase infra § 5). Caracterizando los planes como un "fenómeno interesante e iluminador", lo que tengo en mente aquí es el conjunto de regularidades y de normas a ellos asociadas (tales como coherencia medio a fin, consistencia entre planes y planes-cum-creencia, aglomeración, estabilidad razonable) que Bratman identifica ${ }^{11}$. Precisamente, este conjunto de regularidades, y los requerimientos normativos asociados a ellas, hacen de la actividad de planificación un objeto teóricamente interesante y vuelven la teoría de los planes de Bratman una concepción iluminadora de la agencia humana. Ahora bien, desde mi punto de vista, cuando se trata de "planificar" para otros, este conjunto de fenómenos no está en juego (lo que no significa negar que otro tipo de fenómenos, similares, puedan estarlo). "Planificar" para otros conlleva, en cambio, el viejo y conocido abanico de cuestiones relativas a la autoridad, la fuerza obligatoria, el poder la coerción, etc. No ganamos nada recurriendo a una mera reformulación de esta red de cuestiones interrelacionadas utilizando los términos de la planificación. Es más, algunas distinciones resultarán debilitadas. En el caso de la tercera persona, hablar de "planes" - planes adoptados por una determinada persona para otra- no ofrece ninguna perspectiva nueva o iluminadora. Por lo tanto, tampoco puede ofrecernos ninguna perspectiva o enfoque nuevo con relación al derecho. Esta, creo yo, es la conclusión a la que inevitablemente llegaremos luego de analizar algunos de los argumentos de Shapiro que analizaré a continuación.

\section{La autoridad de los planificadores}

Argumentaré que, en algunos pasajes cruciales, Shapiro se apoya ilegítimamente en la normatividad que los planes (bratmanianos) poseen

${ }^{11}$ Bratman, M. E., Intention, Plans, and Practical Reason, Cambridge (Mass.), Harvard University Press, 1987; Bratman, M. E., Faces of Intention. Selected Essays on Intention and Agency, Cambridge, Cambridge University Press, 1999; Bratman, M. E., "Intention, Practical Rationality, and Self-Governance", Ethics, 119, 2009, pp. 411-443. 
¿Hay algo que los planes puedan hacer por la teoría del derecho?

respecto del agente (o los agentes) que planifica para sí mismo, con la finalidad de sostener que el derecho también es normativo (i.e., es "obligatorio", tal como lo pone Shapiro) $)^{12}$-aun cuando esa normatividad no proviene de su legitimidad moral-.

La razón en virtud de la cual, según Shapiro, "entender que las normas jurídicas fundamentales son planes no solo vindica la concepción positivista, sino que ofrece una solución convincente a nuestra paradoja respecto de cómo es posible la autoridad jurídica" es en última instancia que "la creación y la persistencia de las reglas fundamentales del derecho se funda [sic] en la capacidad que poseen todos los individuos de adoptar planes"13. Existe, por lo tanto, una "capacidad" peculiar cuando se trata de planes. Esta potestad, señala Shapiro, "no nos es conferida por la moral"14. Cierto. Pero entonces, ¿de qué tipo de capacidad o poder se trata?

La respuesta -de Bratman- es la siguiente: formar una intención, o adoptar un plan, es un tipo especial de "compromiso" mediante el cual nos damos a nosotros mismos un "esquema de razones" (véase infra, $\S$ $6, s u b[5])$ y a través del cual quedamos sujetos a un conjunto específico de exigencias normativas ${ }^{15}$. Gracias al ejercicio de esta capacidad -es decir, en virtud de la creación y la adopción de un plan- los individuos crean, y se sujetan a, ciertas exigencias normativas. De ahora en adelante, denominaré a esta capacidad "la autoridad de los planificadores"16. Esta última debe ser entendida, tal como hemos visto, como

${ }^{12}$ Nótese que lo que está en juego aquí, en la teoría del derecho como plan, es la posibilidad de concebir el derecho como "vinculante" (Shapiro, S. J., op. cit., pp. 211212, 252, 271), o, como Shapiro dice en una ocasión (ibidem, p. 214), como provisto de "fuerza vinculante". En otras palabras, lo que está en juego es "cómo es posible la autoridad del derecho" (ibidem, p. 160).

13 Ibidem, pp. 160-161.

14 Ibidem, p. 161.

${ }^{15}$ Bratman, M. E., Intention, Plans, and Practical Reason, op. cit., cap. 7.

${ }^{16}$ La autoridad en cuestión no tiene que ver, directamente, con la autonomía, o la autogestión y el autogobierno. Las tesis de Bratman acerca de (lo que llama) "autoridad agencial" -la autoridad que una actitud puede tener para hablar por el agente- son bastante complejas (véase Bratman, M. E., Structures of Agency. Essays, op. cit., y Bratman, M. E., "Intention, Practical Rationality, and Self-Governance", op. cit.), y no es necesario detenernos sobre ellas aquí. Las intenciones, y las actitudes similares a 
un tipo especial de poder que da lugar a compromisos y, por lo tanto, crea ciertas exigencias normativas.

¿Cómo es posible que la autoridad de los planificadores dé lugar a "una solución convincente a nuestra paradoja respecto de cómo es posible la autoridad jurídica" 17 ? La idea central de Shapiro parece ser la siguiente (o, al menos, no logro ver otro argumento alternativo a favor de lo que escribe): al igual que, en virtud de su propia autoridad, los planificadores pueden dar lugar a exigencias normativas; del mismo modo, mediante la creación y la adopción de planes, los funcionarios pueden dar lugar a exigencias normativas y, por lo tanto, imponer tales exigencias a los individuos relevantes -su autoridad ("autoridad jurídica") consiste precisamente en hacer eso-. La autoridad de los funcionarios es por lo tanto nada más y nada menos que un caso especial de autoridad de los planificadores.

Existe, sin embargo, una cuestión importante que, creo, debe ser señalada. La "capacidad que poseen todos los individuos de adoptar planes" 18 -que ha de ser entendida, tal como hemos visto, como la capacidad para asumir un tipo especial de compromiso y constituye fuente de exigencias normativas- es la capacidad que cada individuo posee para adoptar planes para sí mismo ${ }^{19}$. En cambio, lo que está en juego cuando se trata de la autoridad jurídica es principalmente la creación de planes para otros. Y, cuando la cuestión es la de una autoridad adoptando planes para otro - esto es, diciéndoles qué hacer ("las instituciones jurídicas planifican para las comunidades sobre las que pretenden tener autoridad [...] diciendo a sus miembros qué pueden, o no pueden, hacer" ${ }^{20}$ ) - todo el abanico de cuestiones referidas a la autoridad social, política y jurídica se presenta nuevamente. Nada ha sido dicho todavía para resolver las bien conocidas paradojas.

las intenciones (e.g., los planes) no poseen, en cuanto tales, este tipo de autoridad y tampoco la creación o la adopción de aquellos constituye un ejercicio de esta última.

17 Shapiro, S. J., op. cit., p. 160.

18 Ídem.

${ }^{19}$ La importante excepción de las intenciones compartidas será abordada más abajo, 5, y 6, sub (1).

${ }^{20}$ Shapiro, S. J., op. cit., p. 200-201. 
¿Hay algo que los planes puedan hacer por la teoría del derecho?

Ahora bien, concedamos que la capacidad que cada uno de nosotros posee para adoptar planes "no nos es conferida por la moral", sino que más bien "es una manifestación del hecho de que somos seres que planifican" (i.e., se trata de un componente central del "especial tipo de psicología" característica de los seres humanos adultos en el mundo moderno ${ }^{21}$ ). Esto, en sí mismo, no muestra todavía que todos nosotros tenemos ese mismo tipo de capacidad de adoptar planes para otros, es decir, la misma capacidad (entendida en términos bratmanianos) para asumir un tipo especial de compromiso y fuente de exigencias normativas. Tampoco muestra que esta última capacidad, en el caso de que exista, "no nos es conferida por la moral". La autoridad que cada uno de nosotros posee para crear y adoptar planes para uno mismo es algo que nos viene dado por los principios de la racionalidad instrumental. Esto es, existe una presión de racionalidad (instrumental) en favor de la planificación, que fundamenta las exigencias normativas a las que esa actividad está sometida (coherencia medio a fin, por ejemplo) ${ }^{22}$. Pero, ¿por qué deberíamos suponer que todo ello también se aplica cuando se trata de la "planificación" para otros?

$\mathrm{Al}$ respecto, hay un pasaje central que citaré de manera completa para luego comentarlo. Cuando una persona adopta un plan personal, dice Shapiro (nótese que se está considerando aquí, específicamente, el caso de la adopción de planes personales), "se sitúa [dado que los "planes son normas"] bajo la regulación de una norma. Esta facultad de auto-regulación le es conferida por los principios de la racionalidad instrumental"23. La capacidad en cuestión es, por lo tanto, una "facultad de auto-regulación". No es la moral la que confiere ese poder a $X$ (véase también el pasaje de p. 160, citado más arriba), ese poder se posee en virtud de "los principios de la racionalidad instrumental". Esto ha de entenderse como una consecuencia del hecho de que la

21 Tal como sostiene Bratman (Shapiro, S. J., op. cit., p. 160).

22 Bratman, M. E., Intention, Plans, and Practical Reason, op. cit.; Bratman, M. E., "Intention, Belief, Practical, Theoretical", en Robertson, S. (ed.), Spheres of Reason, Oxford, Oxford University Press, 2009, pp. 29-62; Bratman, M. E., "Intention, Practical Rationality, and Self-Governance", op. cit.

${ }^{23}$ Shapiro, S. J., op. cit., p. 169. 
planificación posee, tal como Shapiro (siguiendo al Bratman ${ }^{24}$ ) sostiene en una de las subsecciones precedentes, un "sentido pragmático"25. Es decir, existen buenas razones pragmáticas, o instrumentales (tales como la complejidad de fines, los recursos escasos, la "desconfianza en nuestro yo futuro" ${ }^{26}$ ) a favor de que los seres humanos se embarquen en la actividad de planificación.

Todo esto lo sabemos ya. Pero leamos todavía más. "Cuando una persona adopta un plan personal, se sitúa [dado que "los planes son normas"] bajo la regulación de una norma. Esta facultad de auto-regulación le es conferida por los principios de la racionalidad instrumental. Los seres que planifican [continúa Shapiro], en otras palabras, tienen la capacidad racional de sujetarse a normas"27. Aquí ha de entenderse que la planificación, en el sentido relevante, se relaciona con el gobierno de sí mismo (o autogobierno). De ello no se sigue que las criaturas planificadoras posean la capacidad racional de imponer normas a otras criaturas (capacidad que ha de ser entendida, del mismo modo, como "poder para gobernar", es decir, como el poder para poner a alguien "bajo la regulación de una norma"). Por ello, esta última afirmación se encontraría, al menos hasta este punto, infundada. Es por ello que debería explicarse en qué consiste esta última capacidad y cuál es su origen. Es cierto, puede darse ocasionalmente el caso de que formulemos, para otros, normas de conducta que son instrumentalmente racionales. Pero el éxito de tal empresa depende de muchas otras cosas además del poder que, por hipótesis, tendríamos qua criaturas planificadoras. (La primera pregunta que me viene en mente es, obviamente, la siguiente: “"instrumentalmente racionales" desde el punto de vista de quién? Véase infra, en esta sección). El poder que $X$ tenga para imponer normas a otros, si y cuando lo tenga, ciertamente no es algo que posea simplemente en virtud de ser una criatura planificadora.

${ }^{24}$ Bratman, M. E., Intention, Plans, and Practical Reason, op. cit.

25 Shapiro, S. J., op. cit., p. 164.

26 Ídem.

${ }^{27}$ Ibid., p. 169. 
¿Hay algo que los planes puedan hacer por la teoría del derecho?

Pero -se objetará- Shapiro está hablando aquí de los planes personales; y por lo tanto no sorprende que su tesis no se aplique al caso de la "planificación" para otros.

Sin embargo, las cosas no son así de simples. Continúa Shapiro:

En efecto, esta capacidad explica la eficacia de la planificación. La psicología de la planificación es singular no solo porque permite a los planificadores la formación de estados mentales que controlan la conducta futura, sino en tanto les permite reconocer que la formación de estos estados genera una presión racional para actuar en consecuencia ${ }^{28}$.

Pero ¿esto se aplica solo a los planes personales, o también al derecho (recuérdese que el derecho es un caso de "planificación para otros")? Si se aplica también al derecho, entonces aquí hay algo que no funciona. ¿Por qué debería aceptar, en virtud únicamente del hecho que compartimos una "psicología planificadora", que los planes que tú has hecho y adoptado para mí, me ponen bajo una "presión racional de respetarlos"? Ciertamente se necesita algo más -ya sea la moral, o razones prudenciales-. "Así [el texto continúa], cuando un individuo adopta un plan de autoregulación, la disposición a seguirlo no se asemeja a un puro reflejo; por el contrario, está mediada por el reconocimiento de que el plan es un estándar justificado de conducta e impone una exigencia racional de llevarlo a cabo" 29 . Debe subrayarse, creo, que todo esto no se aplica al caso de la "planificación para otros" y por lo tanto tampoco se aplica al derecho. Shapiro no dice que se aplique y -como veremos más abajo- incluso en algunos lugares argumenta lo contrario. Pero, y este es mi punto, Shapiro no es del todo claro sobre esta cuestión; no siempre asume la misma posición al respecto. La esencia de la teoría del derecho como plan es, precisamente, que aquello que permite explicar la naturaleza del derecho es nuestra psicología planificadora, es decir, que "comprender el derecho implica comprender nuestra especial psicología [como agentes que planifican] y las

${ }^{28}$ Ídem, cursivas agregadas.

29 Ídem. 
normas de racionalidad que regulan su correcto funcionamiento" 30 ; y, además, "la creación y la persistencia de las reglas fundamentales del derecho se funda en la capacidad que poseen todos los individuos de adoptar planes" 31 . La "racionalidad interna" del derecho ${ }^{32}$, basada en las exigencias impuestas por la racionalidad de la planificación, proviene de esa capacidad. Por ello, creo, existe una analogía, o una identificación, no argumentada entre el caso de la primera persona (ya sea "yo" o "nosotros", véase infra § 5) y de la tercera persona.

Escribe Shapiro:

En lo que sigue, mi propósito será teorizar sobre la base del análisis del capítulo anterior, demostrando que las tecnologías de la planificación incluso las más complejas que son activadas por el derecho, pueden ser construidas mediante la agencia humana exclusivamente. En otras palabras, para construir o hacer funcionar un sistema jurídico no se necesita tener la legitimidad moral de imponer obligaciones jurídicas y conferir derechos jurídicos: solo se necesita la capacidad de planificar ${ }^{33}$.

Ahora bien, esta última afirmación que he puesto en cursivas es, desde mi punto de vista, sorprendente. Puesto que sugiere que los sistemas jurídicos, si bien no son necesariamente el resultado del ejercicio de una autoridad moral, se distinguen, obviamente, de una mera estructura de órdenes e incentivos, por más compleja que sea. Ello en cuanto los sistemas jurídicos poseen algún tipo de autoridad ("autoridad jurídica"34). Y se distinguen porque son el resultado del ejercicio de nuestra habilidad para planificar, $i$. e., porque gozan de la autoridad que poseemos como planificadores. "La existencia del derecho, entonces, refleja el hecho de que los seres humanos somos seres que planifican, dotados de capacidades cognitivas y volitivas para organizar el com-

30 Ibidem, p. 161.

31 Ibidem, pp. 160-161.

32 Ibidem, p. 231.

${ }^{33}$ Ibidem, p. 202. Cursivas agregadas.

34 Ibidem, p. 160. 
¿Hay algo que los planes puedan hacer por la teoría del derecho?

portamiento a lo largo del tiempo y entre las personas a fin de alcanzar metas muy complejas"35.

La afirmación según la cual existe, en el argumento de Shapiro, una analogía, o una identificación, infundada entre los casos de la primera y de la tercera persona resulta corroborada, creo, por el pasaje que se encuentra en p. 170:

mientras que todos los planes son normas intencionales positivas, no todas las normas intencionales positivas son planes. Las amenazas son creadas por la acción humana, y son creadas para guiar la acción, pero no son normas típicamente estructuradas: a diferencia de los planes, no son característicamente parciales, ni compuestas, ni tienen una estructura anidada.

Esto sugiere que la differentia de los planes es su estructura. La sugerencia es, sin embargo, equivocada a la luz de lo que sigue a continuación:

Más importante, estas normas [las amenazas] no están destinadas a guiar la conducta decidiendo cómo actuar, ni pretenden resolver tales cuestiones. [Más abajo discutiré el significado que "resolver" posee aquí, 6, sub (5)]. Las amenazas se supone que han de ser meramente, y se pretende que sean, un factor a ser considerado entre muchos otros. No es irracional o irrespetuoso deliberar sobre si uno debe rendirse ante la amenaza - el asaltante, después de todo, le da una opción: 'el dinero o la vida'. En cambio, cuando uno ha adoptado un plan, para sí mismo $o$ para otra persona, el plan debería excluir las deliberaciones sobre sus méritos, y también tiene la pretensión de brindar una razón para excluir las deliberaciones sobre sus méritos ${ }^{36}$.

Así, la differentia de los planes es (lo que podríamos llamar) su "fuerza excluyente". Pero nótese que los planes solamente pretenden poseer fuerza excluyente (i. e., reclaman autoridad) $-\mathrm{y}$, por lo tanto, preten- 
den "excluir", u "ofrecer razones para excluir", la deliberación-. ¿Está queriendo decir Shapiro que, al contrario de lo que sucede en el caso de las amenazas, cuando se trata de un plan adoptado por X para $\mathrm{Y}$, el hecho que $\mathrm{Y}$ delibere sobre si dejar que sus acciones se guíen por el plan adoptado por $\mathrm{X}$ muestra algún tipo de irracionalidad o falta de respeto por parte de Y? Shapiro no dice eso, en cambio, escribe que si bien en el caso de las amenazas ello no es muestra de irracionalidad, los planes, hayan sido adoptados para quien planifica o para otros, se suponen destinados a excluir (y tienen la pretensión de ofrecer razones para excluir) la deliberación. Bien. Pero argumentando en este sentido, Shapiro no advierte una importante diferencia entre los planes personales y los "planes" creados para otros. Mientras (tal como se sigue de cualquier teoría aceptable sobre la razonable estabilidad de los planes) hay un tipo de irracionalidad que se manifiesta cuando constantemente se reconsideran lo planes personales una vez adoptados, y también hay un tipo de irracionalidad que se manifiesta al considerar un plan personal, ya adoptado, como una razón más que ha de ser balanceada junto a todas las demás razones relevantes aplicables al caso (esto puede llevar a ciertas paradojas de circularidad: los planes, según Bratman, funcionan como "esquemas de razones" 37 , y dan lugar a problemas relativos a los medios, los pasos preliminares, la elección de opciones relevantes y el descarte de opciones inconsistentes con ellos), por el contrario, analizar si seguir o no un "plan" que otra persona ha adoptado para uno, o sopesar el hecho de que alguien ha adoptado un "plan" para mí junto a las demás razones de primer orden relevantes, no implica, en sí mismo, ningún tipo de irracionalidad. Y esta es una profunda diferencia. Bajo este aspecto, los "planes" adoptados para otros se encuentran al mismo nivel de las órdenes respaldadas por amenazas y otros tipos de prescripciones basadas en incentivos. Entonces, ¿dónde está la diferencia? ${ }^{38}$. Cuando "planificamos" para otros, lo que hacemos es, banalmente, formular

${ }^{37}$ Bratman, M. E., Intention, Plans, and Practical Reason, op. cit.

${ }^{38}$ Recuérdese que, dadas las premisas básicas y los propósitos de la teoría del derecho como plan, Shapiro no puede recurrir a la respuesta obvia: los planes legales no son meras órdenes respaldadas por amenazas, sino que consisten en dictados de una autoridad moralmente legítima. 
¿Hay algo que los planes puedan hacer por la teoría del derecho?

órdenes o, más en general, formular prescripciones basadas en incentivos ("amenazas" dice aquí Shapiro) ${ }^{39}$.

En otras palabras. Concedamos, tal como sostiene Bratman, que los planes deben su autoridad a la racionalidad instrumental y que se encuentran sujetos a sus normas. La racionalidad instrumental es la racionalidad en la consecución de fines, propósitos. ¿Los propósitos y los fines de quién? En el caso de la planificación en primera persona, la respuesta es clara: mis fines y propósitos (o quizás nuestros fines y propósitos, véase infra § 5), cualquiera sea el modo en que hayan de determi-

${ }^{39}$ En la sección "La introducción de la jerarquía" (Shapiro, S. J., Legalidad, op. cit., p. 184 y ss.) lo que el chef principal hace es, banalmente, formular órdenes ("es decir, puedo ordenarles hacerlo", ibidem, p. 185). Es únicamente en virtud de que nosotros, los chefs asistentes, aceptamos los planes adoptados para nosotros, o porque aceptamos la autoridad del chef principal, que sus órdenes son vinculantes para nosotros (acerca del papel de la aceptación y el consentimiento en el argumento de Shapiro, véase infra $\S 6$, sub [2]). Shapiro escribe (ibidem, p. 185): "cuando el chef principal ordena realizar alguna acción al asistente, puede decirse que 'adopta un plan' para él”. Entonces, ¿cualquiera puede, a voluntad, adoptar planes para mí? No, pero no sorprende que si acepto los planes que otra persona adopta (i. e., adopción, en primera persona, del plan) y asumo el compromiso de llevarlos a cabo, entonces se me aplican las exigencias normativas que gobiernan la planificación. Por lo tanto, "al emitir la orden, el chef principal coloca al asistente bajo una norma pensada para guiar su conducta y para ser empleada como estándar de evaluación. Además, el chef principal no pretende que su orden sea tratada como una consideración más a tener en cuenta cuando el asistente planifique qué hacer. Por el contrario, pretende que decida la cuestión a su favor. Y como el asistente acepta la relación jerárquica, adoptará el contenido de la orden como plan [cursivas mías] y revisará sus otros planes para que sean consistentes con la orden. Tratará la orden como si él la hubiera formulado y adoptado" (idem). De nuevo: "una parte del plan compartido autoriza a ciertos miembros del grupo a elaborar o aplicar las otras partes del plan. Estas 'autorizaciones' son aceptadas cuando los miembros del grupo acuerdan ceder su potestad exclusiva de planificar y se comprometen a conformarse a los planes formulados y aplicados por los miembros autorizados [cursivas mías]. Por tanto, cuando alguien autorizado por el plan compartido emite una orden, extiende de ese modo el plan y brinda a los miembros del grupo nuevos subplanes a los cuales han de conformarse" (ibidem, p. 186). Cuando otra persona adopta un plan para mí, y yo mismo lo adopto -o me comprometo a ello (quizás, porque de algún modo le he transferido el poder de adoptar planes para mí)- entonces tengo un plan. ¿Es esto todo lo que Shapiro intenta decir? ¿O, en cambio, la teoría del derecho como plan afirma que, como cuestión de necesidad conceptual o de la "naturaleza fundamental" del derecho, los individuos afectados por el derecho adoptan los planes legales? (Véase infra $\S 6, s u b[2])$. 
narse tales fines o propósitos. Pero, en el caso de los "planes" adoptados para otros, surge una disyuntiva. Estamos hablando de normas que son instrumentalmente racionales ipara quien planifica o para aquellos respecto de los cuales el "plan" es adoptado? A menos que presupongamos que ambos coinciden -lo que sería una asunción infundada-debemos conceder que lo que es instrumentalmente racional para uno puede no serlo para los otros, y viceversa ${ }^{40}$. La idea de que las normas jurídicas son planes con un fundamento pragmático y que están sujetas a las exigencias que la racionalidad instrumental impone a los planes, descansa, parece, en la asunción según la cual nosotros -todos los funcionarios y los ciudadanos de a pie-compartimos los mismos fines y propósitos relevantes. Es decir, supone que todos los individuos involucrados en el funcionamiento de un sistema jurídico necesariamente comparten los mismos propósitos o fines relevantes, como una cuestión de necesidad conceptual, o relativa a la "naturaleza fundamental" del derecho. Pero esto parece ser demasiado irénico, y de todos modos es una cuestión puramente contingente (véase también infra, $\S 5$ ).

Así, no parece ser cierto que "entender que las normas jurídicas fundamentales son planes [...] ofrece una solución convincente a nuestra paradoja respecto de cómo es posible la autoridad jurídica" 41 . De ello resultaría entonces que las normas jurídicas no son, en cuanto tales (i.e., simplemente qua normas jurídicas) planes. Las normas de racionalidad a las que se encuentran sujetas las normas jurídicas no son las normas de racionalidad que gobiernan el correcto funcionamiento

${ }^{40}$ La dificultad puede advertirse con claridad, desde mi punto de vista, cuando Shapiro propone su solución a la paradoja de la autoridad (Shapiro, S. J., op. cit., p. 228-229): "los funcionarios públicos tienen la potestad de adoptar el plan compartido que establece estas reglas fundamentales en virtud de las normas de la racionalidad instrumental. Puesto que estas normas que confieren la capacidad racional de planificar no son planes ellas mismas, no han sido creadas por ninguna otra autoridad. Existen solo en virtud de que son principios racionalmente válidos". ¿Los fines de quién son servidos por las reglas fundamentales de un sistema jurídico, y quién se encuentra sometido a las presiones de la racionalidad en cuestión?

41 Shapiro, S. J., op. cit., p. 160. 
¿Hay algo que los planes puedan hacer por la teoría del derecho?

de nuestra especial psicología como agentes planificadores ${ }^{42}$. (Podría darse que "comprender el derecho implica comprender nuestra especial psicología [como agentes que planifican] y las normas de racionalidad que regulan su correcto funcionamiento" 43 , pero, hasta aquí, nada ha sido dicho para mostrar que así sea).

En definitiva, parece falso que "la creación y la persistencia de las reglas fundamentales del derecho se funda en la capacidad que poseen todos los individuos de adoptar planes" 44 . Todo lo que Shapiro ha mostrado es, en cambio, que están basadas en nuestra capacidad para formular "amenazas" y otros tipos de prescripciones apoyadas en incentivos ${ }^{45}$.

\section{Un diagnóstico preliminar}

Entonces, para repetir, me parece que, en ciertos puntos centrales de su argumento, Shapiro se apoya en la normatividad (bratmaniana) de la planificación en primera persona (i. e., en la autoridad de los planificadores, véase supra $\S 3$ ) para afirmar que el derecho también es normativo. Normativo en un sentido que no involucra legitimidad moral (con la finalidad de explicar "cómo es posible la autoridad

42 A la cuestión de la violación de una norma (i. e., la no observancia deliberada de la norma) corresponde, en el caso de las intenciones y los planes, la cuestión de la tentación. Para Bratman, la clave racional para resistir a la tentación está en que el agente anticipe las quejas futuras (Bratman, M. E., Faces of Intention. Selected Essays on Intention and Agency, Cambridge, Cambridge University Press, 1999, cap. 4; Bratman, M. E., Structures of Agency. Essays, op. cit. cap. 12). Esto tiene sentido ya que, en el caso de las intenciones y los planes, el agente es siempre el mismo, el planificador. No veo cómo instaurar un paralelo con las normas jurídicas.

${ }^{43}$ Shapiro, S. J., op. cit., p. 161.

${ }^{44}$ Ibidem, pp. 160-161.

${ }^{45}$ Lo que no significa negar la posibilidad de que existan normas de racionalidad a las cuales estén sujetas las normas jurídicas, en cuanto prescripciones. Como tampoco significa negar que exista presión racional de coherencia medio a fin, consistencia y aglomeración que deriven de tales normas de racionalidad. Las normas que definen "la racionalidad interna del prescribir" pueden ser identificadas, a partir de asunciones derrotables sobre la psicología de quienes prescriben (Celano, B., Dover essere e intenzionalità. Una critica all'ultimo Kelsen, Torino, Giappichelli, 1990, pp. 127-150, 187-191, 269-282). 
jurídica" $\left.{ }^{46}\right)$. Los planes son, de hecho, normativos ${ }^{47}$, y su normatividad se basa en normas de racionalidad instrumental. Sin embargo, esto no es así cuando, como en el caso del derecho, "planificamos" para otros, i.e., les decimos qué tienen que hacer, quieran o no, y les ofrecemos incentivos para hacerlo. Shapiro reconoce que el derecho pretende poseer fuerza moral vinculante, y que puede fracasar en ello. Pero de todos modos no deberíamos establecer por mera definición, o como un punto conceptual o una cuestión de su "naturaleza fundamental", que cuando el derecho tiene éxito y posee fuerza moral vinculante, la posee en virtud de normas de racionalidad instrumental ${ }^{48}$.

${ }^{46}$ Shapiro, S. J., op. cit., p. 160.

${ }^{47}$ Esto es un atajo para decir que la adopción de un plan es una forma especial de compromiso, sujeta a específicas exigencias normativas.

${ }^{48}$ Mi punto es, por lo tanto, que la analogía relevante entre la planificación individual, por un lado, y la "planificación" jurídica, por el otro, no se sostiene. Shapiro explícitamente sostiene que pretende invertir la analogía platónica entre alma y Estado (Shapiro, S. J., op. cit., p. 243 y ss.). En lugar de pasar de una investigación acerca de la naturaleza de (la justicia en) el Estado, a una investigación acerca del individuo; Shapiro pasa de una investigación acerca del individuo como agente planificador a considerar el derecho como un conjunto de planes. Las normas jurídicas, sostiene, "cumplen en la vida social la misma función que las intenciones cumplen en la agencia individual y compartida: son medios universales que nos permiten coordinar nuestra conducta intra e interpersonalmente" (ibidem, p. 244). Pero, creo yo, la primera parte de este enunciado es equivocado, por las razones que he intentado ofrecer. La segunda parte bien puede ser cierta. De hecho, muchos aspectos de la analogía individuo-Estado, en la versión de Shapiro, resultan, creo yo, correctos. Véase, por ejemplo, en ibidem, p. 250: "al caracterizar la actividad jurídica como una actividad de planificación, mi propósito ha sido iluminar la naturaleza gradual del comportamiento regulador del derecho. Pero el paralelismo no acaba aquí. Como deseo mostrar, la actividad jurídica también persigue los mismos objetivos básicos que los planes comunes y ordinarios, a saber, guiar, organizar y controlar la conducta de los individuos y los grupos. Lo hace contribuyendo a que los agentes reduzcan sus costes de deliberación, negociación y celebración de acuerdos, incrementen la predictibilidad de su comportamiento, contrarresten la ignorancia y el mal carácter y dispongan de formas de responsabilidad". No tengo nada que decir contra ello. Tampoco respecto de lo siguiente (ibidem, pp. 253-254, en cap. 7): "como he intentado mostrar en los últimos capítulos, no toda forma de guiar la conducta cuenta como 'planificación'. En efecto, la planificación es una manera muy particular de guiar la conducta. Por esta razón, la Tesis de la planificación realiza una afirmación iusfilosófica fuerte. Según esta, la actividad jurídica no consiste simplemente en la creación y aplicación de reglas. Es un proceso incremental cuya función es guiar, organizar y 
¿Hay algo que los planes puedan hacer por la teoría del derecho?

Si se concede que hemos encontrado en el argumento de Shapiro una analogía, o identificación, infundada, ¿de dónde proviene? Mi diagnóstico preliminar es el siguiente.

Shapiro refuerza el vínculo entre los planes y las intenciones, y esto le trae algunos problemas. La teoría de los planes de Bratman es, primero y sobre todo, una teoría de la intención como plan. Una de las piedras basales de la teoría de los planes de Bratman es que los planes son "intenciones extendidas" y que, en consecuencia, las intenciones han de ser entendidas como elementos que componen los planes -las intenciones son, podríamos decir siguiendo a Bratman, el material del que están hechos los planes- ${ }^{49}$. Las normas jurídicas, sin embargo, no so intenciones "extendidas". Lo que interesa a Shapiro, para ofrecer un esquema conceptual que permita comprender el derecho, son los "planes" en un sentido mucho más débil, menos informativo y no bratmaniano. En la "planificación" jurídica, las formas de compromiso y las exigencias de racionalidad que son características de los planes bratmanianos ${ }^{50}$ (coherencia medio a fin, consistencia, aglomeración, razonable estabilidad), o bien no se verifican o se verifican en un modo bastante diferente. Un modo este último que es, podríamos decir sobre la base de lo que hasta aquí ha probado Shapiro, característico de las órdenes, las amenazas y, en general, de las prescripciones basadas en incentivos ${ }^{51}$.

Apelar a los planes parece, a primera vista, promisorio para la teoría del derecho por dos razones. Los planes son un tipo de normas (1)

controlar el comportamiento mediante la resolución de cuestiones normativas y que, en condiciones normales, dispone a sus destinatarios a cumplir". En estos pasajes, la noción relevante de plan es una noción más bien débil, mucho menos exigente que la elaborada por Bratman (véanse infra, n. 52 y 81).

49 Del mismo modo, lo que interesa a Bratman, en cuanto se refiere a formas de socialidad (véase infra, §5), son las intenciones compartidas (que están presentes tanto en ACC, como, si bien de manera menos exigente, en ACI). (El modo en que Bratman trata el "caso de la Mafia" como actividad compartida - en Bratman, M. E., Faces of Intention. Selected Essays on Intention and Agency, op. cit., pp. 100, 117-118; Bratman, M. E. "Modest Sociality and the Distinctiveness of Intention", Philosophical Studies, 144, 2009, p. 158me parece demasiado oscuro. Pero ello no es de todos modos relevante aquí).

${ }^{50} \mathrm{O}$ de las intenciones compartidas bratmanianas (infra, $\S 5$ ).

${ }^{51}$ Es decir, un modo que permite definir lo que puede denominarse "la racionalidad interna del prescribir" (supra, n. 45). 
positivas y (2) provistas de autoridad (una autoridad que proviene de los principios de la racionalidad instrumental). Por lo tanto, podría resultar que recurriendo al concepto de plan -es decir, sosteniendo que las normas jurídicas son planes y que la clave para entender la naturaleza del derecho es nuestra especial psicología como agentes planificadores- sea posible resolver, en vena positivista, las conocidas paradojas acerca del derecho que provienen de su doble naturaleza (el derecho es un hecho social y además, al menos prima facie, es normativo). Las apariencias sin embargo pueden ser engañosas. Solo los planes personales (autoimpuestos) poseen, en cuanto tales, ambas propiedades (ser positivos y provistos de autoridad). Los "planes" adoptados para otros son, efectivamente, positivos, pero en cuanto tales no poseen ninguna autoridad. $\mathrm{Si}$, y cuando, tales planes - $\mathrm{O}$ sus autores- poseen autoridad, ha de ser establecido sobre otras bases. Bases que son completamente diferentes de la autoridad conferida por los principios de la racionalidad instrumental al autor de un plan autoimpuesto. Las normas jurídicas, sin embargo, son en su mayor parte normas adoptadas para otros. Por lo tanto, si el punto de tratar a las normas jurídicas como planes era la supuesta posibilidad de explicar, de un modo simple y económico, el hecho que son, al mismo tiempo, positivas y autoritativas; la tesis de la analogía -o de la identidad (las normas jurídicas son planes)- se desmorona. Entonces, ¿por qué tratar a las normas jurídicas como planes? Por supuesto, podríamos todavía afirmar que son "planes" creados y adoptados para otros ${ }^{52}$. Pero esto, en sí mismo, no dice mucho más

52 Una aclaración importante. Si Shapiro ha de ser entendido como sosteniendo que los "planes" se distinguen únicamente por su estructura (parcialidad, anidamiento, etc.), entonces no tengo nada que reprocharle. Pero esto equivale a quedarse con el concepto de plan de Bratman. Véase el párrafo final de la sección Planificación Individual del capítulo 5 (Shapiro, S. J., op. cit., p. 162), donde se ofrece lo que parece ser una definición resumida de la noción relevante de plan: "para concluir, un plan es una clase especial de norma. En primer lugar, tiene una estructura característica, a saber, es parcial, compuesta, y anidada. En segundo lugar, es creada por un cierto tipo de proceso, a saber, uno incremental, intencional y que dispone a los destinatarios a cumplir con las normas creadas". No tengo nada en contra de concebir a las normas jurídicas de este modo, por supuesto. Así entendida, la afirmación que las normas jurídicas son planes resulta ser bastante débil (si se la compara con lo que son los planes en la teoría 
¿Hay algo que los planes puedan hacer por la teoría del derecho?

que decir que se trata de normas positivas. Y esto es algo que sabíamos desde el principio ${ }^{53}$.

Quizás podríamos todavía ir más allá para encontrar una explicación al hecho que Shapiro use una analogía o identificación infundada. Shapiro adopta un enfoque desentrecomillado de la validez como fuerza vinculante ${ }^{54}$. Según este enfoque una norma es válida en el caso en que se deba hacer lo que la norma prescribe ("finalmente, tal como emplearé el término, no es necesario que las normas sean válidas. Las normas siempre pretenden indicar lo que debe hacerse o lo que resulta deseable, bueno o aceptable, pero que consigan hacerlo es una cuestión completamente diferente. Una norma que ordena hacer algo que uno no debería hacer es una norma inválida. Es una mala norma, una no-norma"55). No me es del todo claro, sin embargo, si Shapiro piensa que las normas jurídicas (las leyes) son, en cuanto tales, válidas. Me parece que, a veces, el referirse a las normas jurídicas como planes lleva a que Shapiro superponga, respecto de las normas jurídicas,

de Bratman). (Tanto la idea de la parcialidad de las normas jurídicas, como la de la especificación incremental en su aplicación, pueden encontrarse, creo, en la teoría de Kelsen. Lo mismo, por supuesto, sucede con la reflexividad de lo planes, "planes sobre la planificación": el derecho regula su propia producción).

${ }^{53}$ Quizás, al menos algunas de las profundas diferencias que, a pesar de las apariencias, trazan (o al menos eso he sostenido) una división entre la teoría de la agencia como planes de Bratman y el modo en que Shapiro concibe la naturaleza fundamental del derecho, pueden se advertidas a partir de una diferencia ulterior acerca de la ontología de los planes. Una diferencia desconcertante en virtud de su claridad, pero respecto de la cual no es sencillo determinar sus implicaciones y su conexión (si existe) con las dificultades que Shapiro enfrenta y que he indicado en el texto. En breve, los planes bratmanianos han de ser entendidos como actitudes, mientras que los "planes" de Shapiro son el contenido abstracto, el objeto, o el contenido de actitudes posibles. Véase respectivamente Bratman, M. E., Faces of Intention. Selected Essays on Intention and Agency, op. cit., p. 37, 248; y Shapiro S. J., op. cit., p. 169 ("por 'plan' no me refiero al estado mental de 'tener un plan'. Las intenciones no son planes, más bien toman a los planes como objeto. Para mis propósitos, los planes son entidades proposicionales abstractas que exigen, permiten o autorizan a los agentes a actuar, o no actuar, de ciertas maneras en ciertas circunstancias").

${ }^{54}$ Acerca de la validez como desentrecomillado, véase Celano, B., "Validity as Disquotation", en Comanducci, P. y Guastini, R. (eds.), Analisi e diritto 1999. Ricerche di giurisprudenza analitica, Torino, Giappichelli, 2000, pp. 35-77.

55 Shapiro, S. J., op. cit., pp. 72-73. 
la existencia con la validez. Además, esta parece ser una estrategia central, si bien oculta, en la construcción de las bases de la teoría del derecho como plan.

Esto puede ser visto, de manera crucial, en los pasajes donde Shapiro introduce su propia solución de la cuestión relativa al derecho y la moral. "¿Por qué podría afirmarse-como hacen los positivistas- que el derecho y la moral no comparten como fundamento las mismas reglas básicas? ¿Por qué la determinación de la validez jurídica depende de una indagación sociológica, antes que moral?"56.

En su respuesta a esta última pregunta, Shapiro parece conectar estrechamente la existencia y la validez:

Espero que mis respuestas a estas preguntas sean evidentes ahora: a saber, que las reglas fundamentales de un sistema jurídico constituyen un plan compartido y, como hemos visto, la manera adecuada de evaluar la existencia y el contenido de un plan compartido es mediante un examen de los hechos sociales relevantes. Un plan social solo existe si fue diseñado con un grupo en mente, de manera que puedan participar en una actividad conjunta, es públicamente accesible y es aceptado por la mayoría de los miembros del grupo en cuestión. Como resultado, si se desea descubrir la existencia o el contenido de las reglas fundamentales de un sistema jurídico, debemos observar exclusivamente estos hechos sociales. En otras palabras, debemos observar solo qué piensan, pretenden, afirman y hacen los funcionarios aqui ${ }^{57}$.

${ }^{56}$ Ibid., p. 224. Cursivas agregadas.

${ }^{57}$ Ibíd., p. 224, Shapiro continúa: "Adviértase además que la existencia de un plan compartido no depende de que se verifique ningún hecho moral. El plan compartido puede ser moralmente repulsivo. Puede ceder el control total de la planificación social a un dictador malevolente o privilegiar los derechos de ciertos subgrupos de la comunidad por encima de otros. El plan compartido puede no tener ningún apoyo de la población general; quienes están bajo su gobierno pueden odiarlo absolutamente. Pese a todo, si tienen lugar los hechos del plan compartido -si la mayoría de los funcionarios acepta un plan públicamente accesible y diseñado para ellos- entonces existirá el plan compartido. Y si el plan compartido establece una actividad de planificación social que es jerárquica y altamente impersonal, y la comunidad en general obedece los planes 
¿Hay algo que los planes puedan hacer por la teoría del derecho?

Entonces, las normas pueden ser válidas (i. e., vinculantes) o no. $\mathrm{Su}$ existencia es una cosa, sus méritos o deméritos, otra. La razón en virtud de la cual resulta iluminador recurrir a los planes es que, claramente, las condiciones de existencia de los planes son independientes de sus méritos o deméritos ${ }^{58}$. Pero, los planes autoimpuestos son normativos en virtud de la autoridad que la racionalidad instrumental confiere a cada uno de nosotros para adoptar planes y políticas. En los pasajes citados (véanse las palabras en cursivas), lo que Shapiro sostiene es que ello arroja luz sobre la validez de las normas jurídicas. Es decir, sostiene que ello explica cómo esas normas pueden determinarse únicamente sobre la base de hechos sociológicos, tal como afirman los positivistas. Pero las normas jurídicas son planes creados para otros y, como tales, no poseen ninguna autoridad sobre (algunos de) sus destinatarios. Es precisamente bajo este aspecto que son completamente diferentes de los planes autoimpuestos y de las intenciones. Sostener que el ser planes explica la validez de las normas jurídicas -y que esa explicación se mantiene dentro de las filas positivistas ya que los planes existen si son adoptados- equivale a eliminar una diferencia relevante.

De todos modos, debemos todavía complicar el cuadro. Shapiro no es ciertamente tan ingenuo como sugiere mi lectura poco caritativa de los pasajes comentados. Shapiro explícitamente reconoce que "el hecho de que alguien adopte un plan para que otros lo sigan no significa que, desde el punto de vista moral, ellos deban obedecer. E1 plan puede ser insensato o malvado, por tanto, salvo que haya costes sustanciales asociados al incumplimiento, los sujetos deberían moral-

creados conforme a él, entonces, también existirá un sistema de autoridad jurídica" (idem).

58 Véase Ibid., p. 160: "Mi estrategia es mostrar que existe otro ámbito cuyas normas solo pueden descubrirse mediante la observación social, no moral, a saber, el ámbito de los planes. El modo adecuado de determinar la existencia de planes, como argumentaré más adelante, consiste simplemente en señalar el hecho de su adopción y aceptación. Que hoy tenga el plan de ir a la tienda, o que esta noche tengamos el plan de cocinar la cena juntos, no depende de que estos planes sean deseables, sino de que de hecho los hayamos adoptado (y nos los hayamos descartado luego). En otras palabras, el positivismo es trivial e incontrovertiblemente verdadero en el caso de los planes: la existencia de un plan es una cosa, sus mérito o demérito otra muy distinta". 
mente abstenerse de 1levarlos [sic] adelante"59. Además, trabaja sobre la teoría de Bratman, agregando aclaraciones, extensiones, distinciones que están destinadas, creo, a evitar las dificultades que, quizás un tanto apresuradamente, he afirmado su teoría no logra superar. Debemos entonces analizar algunas de estas estrategias.

\section{Agencia en primera persona del plural}

Hasta aquí mi argumento se ha apoyado en la afirmación según la cual la adopción de planes por parte de los agentes es relativa a sus propias acciones y deliberación futuras. Bajo este aspecto, he sostenido, la "planificación" legal se diferencia de manera crucial de la planificación propiamente dicha. ¿Significa esto que los planes son relevantes solo cuando se trata de la agencia individual?

Si ello es así, mi argumento se basaría en un grave error. Bratman mismo ha desarrollado y extendido su teoría para dar cuenta de la actividad compartida y otras formas de agencia social ${ }^{60}$. Es en estos casos donde, parece, hacemos planes también para los demás y no solo para nosotros mismos.

Comprensiblemente, Shapiro otorga gran peso a esta extensión que Bratman hace de la teoría de la intención como plan, con la finalidad de dar cuenta de otras formas de agencia social, e intenta capitalizarla. Pero este no es, argumentaré, un camino promisorio.

La actividad jurídica es, sostiene Shapiro, actividad compartida ${ }^{61}$. Aquí, la noción relevante de actividad compartida ha de ser entendida

${ }^{59}$ Ibidem, p. 186.

${ }^{60}$ Bratman, M. E., Selected Essays on Intention and Agency, op. cit., caps. 5-8; Bratman, M. E., "Dynamics of Sociality", Midwest Studies in Philosophy, 30, 2006, pp. 1-15; Bratman, M. E., Structures of Agency. Essays, op. cit., cap. 13; Bratman, M. E., "Modest Sociality and the Distinctiveness of Intention", op. cit.

${ }^{61}$ Véase Shapiro, S. J., op. cit., p. 255: "La Teoría de los planes realiza una afirmación más fuerte. No solo algunos aspectos de la actividad jurídica son compartidos, sino que lo es todo el proceso. La actividad jurídica es una actividad compartida en el sentido de que los diferentes actores involucrados cumplen ciertas funciones en la propia actividad de planificación social: algunos participan creando y afectando planes y 
¿Hay algo que los planes puedan hacer por la teoría del derecho?

como un desarrollo de la idea ofrecida por Bratman de la actividad compartida. Pero, creo yo, el hecho que la actividad compartida sea en primera persona del singular o del plural no produce, respecto de las dificultades señaladas en las secciones anteriores, ninguna diferencia relevante ${ }^{62}$.

¿Por qué? Porque el elemento central de la actividad compartida (bratmaniana) es la intención compartida y el compromiso ${ }^{63}$. E1 modelo es el de un grupo reducido de personas llevando a cabo una actividad bien delimitada, con una finalidad bien definida (cada uno de nosotros "tiene la intención que nosotros hagamos J"). Simplemente, tal como el mismo Shapiro reconoce y enfatiza, el tipo de intenciones y compromisos que, según Bratman, son constitutivos de la actividad compartida no encajan con lo que sucede en la práctica jurídica, cuando se la considera en su totalidad (tal como, según la tesis de la agencia compartida de Shapiro, debería ser vista) ${ }^{64}$. Brat-

otros participan aplicándolos. A cada uno le toca cumplir una parte en la planificación para la comunidad. Llamemos a esto la 'Tesis de la agencia compartida": "la actividad jurídica es una actividad compartida" (idem).

${ }^{62}$ Hablar de agencia en primera persona del plural no es, estrictamente hablando, correcto dentro del modelo de actividad compartida elaborado por Bratman. La concepción de Bratman de la intención compartida posee, de hecho, un espíritu individualista (Bratman, M. E., Faces of Intention. Selected Essays on Intention and Agency, op. cit., pp. 108, 111, 129; Bratman, M. E., "Modest Sociality and the Distinctiveness of Intention", op. cit., p. 163). Las intenciones compartidas bratmanianas son un conjunto de intenciones individuales adecuadamente entrelazadas, que satisfacen ciertas condiciones (Bratman denomina "constructivismo" a su teoría de la intención compartida. La explicación de la intención compartida procede a partir de la "construcción de una estructura de intenciones individuales interrelacionadas, y de las normas que se aplican a, y guían, tales intenciones"; Bratman, M. E., "Modest Sociality and the Distinctiveness of Intention", op. cit., p. 155). Hablar de agencia en primera persona del plural ha de ser entendido, en el texto, de manera correspondiente.

${ }^{63}$ En la socialidad "modesta" (véase infra, en esta sección, sub [1]), "un compromiso respecto de nuestra actividad, similar a las intenciones, funciona en el razonamiento práctico de cada uno de nosotros" (Bratman, M. E., "Modest Sociality and the Distinctiveness of Intention", op. cit., p. 155).

${ }^{64}$ Como es bien sabido, la historia comienza con la afirmación de Jules Coleman según la cual la regla de reconocimiento de un sistema jurídico ha de ser entendida como una Actividad Cooperativa Compartida bratmaniana (o ACC; Coleman, J. L., The Practice of Principle. In Defense of a Pragmatist Approach to Legal Theory, Oxford, Oxford University 
man felizmente acepta que la actividad jurídica puede-algunas veces, en algunos círculos, bajo algunos aspectos- consistir en una Actividad Cooperativa Compartida (ACC) o en una Actividad Conjunta Intencional $(\mathrm{ACI})^{65}$. No tengo nada en contra de esta afirmación, por supuesto. Que algunos grupos de funcionarios jurídicos, o de funcionarios-cum-ciudadanos, puedan, en algunos casos, verse involucrados en una actividad compartida de tipo bratmaniano ( $j o$ incluso en una ACC!), o que sea posible concebir un sistema jurídico que encaje en este modelo, no es algo que mi argumento excluya. En cambio, considero equivocada la afirmación conceptual u ontológica, es decir, la afirmación según la cual necesariamente, como cuestión de su "naturaleza fundamental", el derecho, considerado en su totalidad, siempre y en todo lugar, encaja en ese modelo (i. e., consiste en la planificación compartida, en el sentido de Bratman).

De nuevo, al reforzar la relación entre los planes (bratmanianos) y las intenciones (recuérdese que, según Bratman, los planes son intenciones "extendidas" y las intenciones son los ladrillos de los que están construidos los planes; y esto también es así en la actividad compartida), el recurrir a los "planes" en ámbito de filosofía del derecho se vuelve genérico y poco informativo. No tenemos ninguna razón para suponer que en la "planificación" jurídica, las formas de compromiso que caracterizan a los planes bratmanianos -y a los modelos bratmanianos de actividad y deliberación compartida- tengan algún tipo de espacio. Así, una vez más, nada de lo que Shapiro ha mostrado nos

Press, 2001, dando crédito a Shapiro por la idea básica), y sigue con la afirmación de Shapiro según la cual debería, en cambio, ser entendida (más plausiblemente) como una variación de la Actividad Conjunta Intencional bratmaniana (ACI; Shapiro, S. J., "Law, Plans, and Practical Reason", Legal Theory, 8 (4), 2002; véase la discusión en Celano, B., "La regola di riconoscimento è una convenzione?", en Redondo, M. C. (eds.), "Il "Postscript" di H. L. A. Hart", Ragion pratica, 21, 2003, pp. 347-360). Ninguna de las dos propuestas funciona, tal como rápidamente reconoció Shapiro. A partir de ello Shapiro ha relajado las exigencias bratmanianas, haciendo espacio a participantes alienados en ACM (véase infra).

${ }^{65}$ Bratman, M. E., Structures of Agency. Essays, op. cit., p. 309; véase también Bratman, M. E., "Shapiro on Legal Positivism and Jointly Intentional Activity", Legal Theory, 8,2002 , p. 511, n. 2 y p. 524 , n. 13 . 
¿Hay algo que los planes puedan hacer por la teoría del derecho?

asegura que las normas de racionalidad que gobiernan la actividad de planificar se aplicarán también a la "planificación" jurídica ${ }^{66}$.

El modelo de actividad compartida de Bratman (ACC y, genéricamente, ACI), se muestra así inadecuado respecto del funcionamiento de un sistema jurídico, considerado como un todo. Tal como he afirmado algunas líneas más arriba, el mismo Shapiro reconoce y enfatiza este punto. La noción de Agencia Compartida Masiva (en adelante ACM) tiene precisamente la pretensión de lidiar con esta dificultad y, a su vez, de mantenerse dentro de un esquema bratmaniano más amplio. Sin embargo, encuentro que ACM es una noción problemática. En ACM todos los participantes comparten un plan, pero "Yo tengo la intención de que nosotros hagamos J" no es verdadero respecto de cada uno de ellos, mientras que sí lo es en las ACI bratmanianas. Tal como Shapiro moldea estos conceptos, el compartir un plan y el llevar a cabo la actividad compartida no exigen tener la intención de llevar a cabo la actividad compartida ${ }^{67}$. Esto, sin embargo, no resulta compatible con el punto de vista de Bratman: "si planeo hacer algo, tengo la intención de hacerlo"68.

${ }^{66}$ Acerca de "valoraciones compartidas" véase infra, n. 80.

${ }^{67}$ Véase e. g. Shapiro, S. J., Legalidad, op. cit., p. 179: "compartir un plan no exige que los miembros del grupo deseen o pretendan que el plan sea exitoso" (y véase el ejemplo de Dudley y Stephens, en nn. 11, 12 del cap. 5); ibidem, pp. 193-194: "Para que un grupo actúe en conjunto, no es necesario que pretenda tener éxito en la empresa conjunta. Solo necesita compartir un plan". Lo que explica el actuar juntos es el compartir un plan (ibidem, p. 180; p. 181: "Harry y yo actuamos en conjunto porque compartíamos un plan"; "los planes compartidos son constitutivos de la agencia compartida"; véase también, ibíd, n. 14, p. 181: "La analogía aquí es con la agencia individual: al igual que la acción individual es un comportamiento individual explicable por el plan individual, la acción compartida es un comportamiento grupal explicable por un plan compartido"). Las condiciones adicionales para la existencia de actividad compartida no son aquí relevantes ("el grupo actúa intencionalmente en conjunto solo cuando todos sus miembros cumplen su parte del plan intencionalmente y la actividad tiene lugar por esta razón", ibíd, p. 181; conocimiento común de la existencia del plan, y la disposición a "resuelven sus conflictos de forma pacífica y abierta", idem).

${ }^{68}$ Bratman, M. E., Faces of Intention. Selected Essays on Intention and Agency, op. cit., nota 37. La idea central en la construcción de una intención compartida en la socialidad modesta son las "intenciones de cada uno de nosotros a favor de nuestra actividad conjunta" (Bratman, M. E., "Modest Sociality and the Distinctiveness of Intention", op. cit., p. 155). 
La actividad compartida es, en el modelo de Bratman, una actividad que se explica mediante una intención compartida ${ }^{69}$; correlativamente, las normas que gobiernan la actividad compartida se basan en las normas a las que están sujetas las intenciones individuales ${ }^{70}$.

Así, en ACM, compartir un plan es independiente de tener la intención de que nosotros hagamos $\mathrm{J}$; y esto va en contra del modelo de actividad compartida de Bratman. Podría responderse, por supuesto, lo siguiente: ¿y cuál es el problema? ${ }^{71}$ Una vez más, la cuestión es si hablar de planes en este sentido no-bratmaniano es iluminador. ¿Cambia algo respecto del hablar de normas o, por ejemplo, de órdenes respaldadas por amenazas $\mathrm{u}$ otros incentivos?

La idea central de Shapiro sigue siendo, al final, la de un pequeño grupo de amigos llevando a cabo conjuntamente una actividad bien delimitada y con una meta bien definida. Este modelo no encaja con la práctica jurídica; o, al menos, no deberíamos decretar que encaja necesariamente, como una cuestión de análisis conceptual o relativa a la "naturaleza fundamental" del derecho. Es cierto, Shapiro es bien

${ }^{69}$ El constructivismo de Bratman "persigue [...] articular una profunda continuidad conceptual, metafísica y normativa- entre la agencia de planificación individual y la socialidad modesta" (Bratman, M. E., "Modest Sociality and the Distinctiveness of Intention", op. cit., p. 155). En la n. 12, p. 179, Shapiro observa: "dado que Dudley y Stephens no pretenden actuar en conjunto, no están sujetos a las mismas restricciones de racionalidad que Henry y yo". El cuadro resultante no parece ser, sin embargo, un caso plausible de agencia compartida. ¿Cómo es posible decir en ese caso que estas personas "comparten un plan"?

70 "La teoría persigue, en cambio, generar la normatividad relevante a nivel social, a partir de la normatividad individual ligada primariamente al contenido de las intenciones de cada uno" (Bratman, M. E., "Modest Sociality and the Distinctiveness of Intention", op. cit., p. 161).

${ }^{71}$ Shapiro (Shapiro, S. J., Legalidad, op. cit., cap. 5, nn. 12-13, pp. 179-181) explícitamente discute con Bratman sobre este punto (reforzando el vínculo entre las intenciones de los participantes y el actuar juntos) y sostiene que, para dar cuenta de la actividad conjunta, el requisito de la intención compartida es demasiado "fuerte". A pesar de lo que a veces parece decir Shapiro, no se trata aquí de un mero conflicto de intuiciones relativas a dónde trazar los límites del concepto de actuar juntos, pues ello bien podría ser un mero desacuerdo verbal. En cambio, tal como sostengo en el texto, lo que está en juego aquí es la aplicabilidad misma, a las ACM (y, por lo tanto, al derecho) del concepto de plan de Bratman, y de las propiedades necesarias que se le atribuye. 
¿Hay algo que los planes puedan hacer por la teoría del derecho?

consciente de esto. Él mismo extiende progresivamente el modelo, relajando las exigentes condiciones bratmanianas acerca de las intenciones compartidas de los participantes, hasta el punto de introducir lo que llama ACM. Pero, creo yo, la extensión no logra llevar a cabo el trabajo necesario, por tres razones.

(1) El modelo de ACM no tiene en cuenta un elemento esencial de las "circunstancias" de la legalidad y de la política, a saber, la existencia de conflictos serios y profundos. ACM da espacio a la posibilidad que existan participantes "alienados". Y Shapiro reconoce el carácter controvertido de las cuestiones que el derecho está destinado a resolver. Pero, en ese cuadro, no entra el conflicto serio y profundo -que no es ni la mera "alienación", ni el desacuerdo acerca de cómo resolver juntos una cuestión que todas las partes han identificado del mismo modo-. En términos de teoría de los juegos, Shapiro no toma seriamente en cuenta los dilemas del prisionero, los problemas de free-rider, u otros graves problemas que pone la acción colectiva ${ }^{72}$. Shapiro se limita a

72 Shapiro de hecho discute la adopción de políticas dirigidas a combatir los free-riders en su narración sobre la Isla de los Cocineros, pero tales políticas son concebidas, aquí, como adoptadas conjuntamente por todas las partes interesadas, y como conducentes a la instauración de una economía de mercado. Ciertamente, en esa narración sobre la Isla de los Cocineros, Shapiro también contempla el desacuerdo, la falta de consenso, etc. Pero todos estos factores son concebidos como conducentes a la adopción colectiva y unánime de un plan maestro, compartido en virtud del hecho que todas las partes concuerdan que es necesario resolver conjuntamente cualquier cuestión que resulte decisiva. ("El carácter controvertido de una actividad puede provenir de su complejidad, o del mero hecho de que los miembros del grupo tengan preferencias y valores diferentes. En cualquier caso, es muy importante identificar y resolver de antemano los conflictos potenciales. La función de los planes es resolver las disputas correcta y definitivamente, antes de que se cometan errores y se tornen irreversibles", Shapiro, S. J., Legalidad, op. cit., p. 175). Bajo este aspecto, la teoría de Shapiro parece albergar una filosofía política normativa de corte contractualista y de vertiente lockeana ("el plan que establece la jerarquía para la isla es un plan compartido", ibidem, p. 211). Es verdad que aquí Shapiro afirma a continuación que "no es necesario que la comunidad acepte el plan compartido para que este tenga lugar", ibidem, p. 212: esta cuestión será analizada más abajo, 6, sub (2). El modelo del libre mercado como dispositivo para la solución de conflictos (La planificación para actividades compartidas de pequeña escala, ibidem, p. 171 y ss.) es claramente insuficiente -o al menos se necesita un argumento sustantivo (tanto normativo como empírico) para mostrar que no lo es-. 
considerar problemas de coordinación y de (un tipo limitado de) batalla de los sexos ${ }^{73}$.

(2) El modelo de Bratman da cuenta de casos en los que realizamos una actividad perfectamente delimitada, persiguiendo un fin bien definido. En esos casos, cada uno de nosotros tiene la intención de que nosotros hagamos J. ¿En qué consiste J cuando se trata del derecho, entendido como una ACM? No existe, en el caso de las prácticas jurídicas consideradas como un todo, una actividad bien delimitada (que pueda ser especificada de un modo no vacío $)^{74}$, o, al menos, no deberíamos decretar que necesariamente existe una, como una cuestión del verdadero concepto de derecho, o de la "naturaleza fundamental" del derecho ${ }^{75}$.

(3) La noción de ACM es ella misma, como hemos visto, problemática. Si los participantes no poseen, cada uno de ellos, la intención "que nosotros hagamos J", entonces no hay intención compartida, ni actividad compartida (en el sentido de Bratman). Y tampoco hay un plan compartido à la Bratman (recuérdese que cada vez que planificamos, tenemos una intención). Puede ser que haya aquí "planes" en algún sentido genérico diferente. Pero nada particularmente informativo se seguiría de ello. Puesto que todo lo que Shapiro nos ha mostrado es que en ACM -y, por lo tanto, en el derecho-, las órdenes, respaldadas por amenazas y otros tipos de prescripciones basadas en incentivos desempeñan un papel central.

Esta es la razón por la que, creo yo, el enfoque que Shapiro ofrece de la agencia compartida no logra, al final, despegarse del punto de partida. Es decir, no logra ir más allá de la interacción entre un número reducido de individuos que llevan a cabo una actividad bien delimitada

${ }^{73}$ Se trata quizás de un rasgo que el enfoque de Shapiro comparte con la teoría de Waldron (véase Shapiro, S. J., Legalidad, op. cit.,cap. 6, nota 11, p. 217). Véase: Waldron, J., Law and Disagreement, Oxford, Oxford University Press, 1999 y, sobre este punto, Gaus, G. F., "The Legal Coordination Game", American Philosophical Association Newsletter on Philosophy and Law, 1, 2002, Benditt, T. M., "Acting in Concert or Going It Alone: Game Theory and the Law”, Law and Philosophy, 23 (6), 2004.

74 Por "especificación vacía" entiendo por ejemplo una especificación como "el mantenimiento del sistema jurídico", o "involucrarse en la práctica del derecho", y otras de este tipo.

75 Véase Celano, B., "La regola di riconoscimento è una convenzione?", op. cit. 
¿Hay algo que los planes puedan hacer por la teoría del derecho?

con una meta bien definida. La extensión que Shapiro lleva a cabo se revela problemática, diluye el punto de partida (i.e., el análisis de Bratman) y resulta inadecuada para llevar a cabo la tarea encomendada (explicar qué es el derecho). Dejando las complicaciones de lado, lo que todavía resulta confuso es, básicamente, la asunción según la cual el derecho debe ser entendido a partir del modelo del autogobierno (esté auto por "yo" o por "nosotros"); y que la autoridad del derecho deba ser entendida sobre la base de la autoridad que cada agente, o grupo de agentes, posee para crear y adoptar planes para ellos mis$\operatorname{mos}^{76}$. Pero abandonar esta asunción llevaría, de hecho, a abandonar la noción de plan para explicar la "naturaleza fundamental" del derecho.

\section{Complicaciones adicionales}

(1) Planificar en contextos institucionales. En la sección anterior he avanzado algunas objeciones contra el uso que Shapiro hace de las tesis que Bratman ofrece sobre la agencia compartida. Se me replicará que mis objeciones, por un lado, no toman en cuenta ciertos rasgos importantes del derecho, en virtud de los cuales es bastante natural que los modelos de Bratman de ACI y de intención compartida no sean aplicables directamente a la práctica jurídica. Y, por otro lado, que tales objeciones no advierten, y están en conflicto con, el hecho de que Shapiro mismo reconoce la cuestión e introduce modificaciones a las tesis de Bratman

${ }^{76}$ Nótese que, a pesar de lo que pueda parecer a primera vista, mi objeción no se ve contradicha por el modo en que Bratman trata, en el caso de la intención compartida, la violación patente de la "condición relativa a la determinación" que se aplica a las intenciones (las intenciones pueden razonablemente referirse únicamente a aquello que consideramos podemos determinar por nosotros mismos; Bratman, M. E., Faces of Intention. Selected Essays on Intention and Agency, op. cit., p. 149 y ss.). Es cierto, cuando cada uno de nosotros tiene la intención de que hagamos J, vamos más allá de la autoridad que poseen los planificadores para planificar para sí mismos. La intención compartida es, sin embargo, un sistema de intenciones entrelazadas e interdependientes. Cuando cada uno de nosotros tiene la intención de que hagamos J, la "condición relativa a la determinación" no resulta necesariamente violada porque yo puedo predecir cuál será tu intención (ibidem, p. 157). Esto no encuentra paralelismo en el derecho. 
-específicamente, introduce la noción de ACM con el propósito de dar debida consideración a tales rasgos-. Los rasgos relevantes son la jerarquía, las relaciones de autoridad, y el carácter institucional del derecho. Efectivamente, es cierto que Bratman en repetidas oportunidades ${ }^{77}$ enfatiza que su enfoque de la actividad compartida y de la intención compartida hace abstracción de "las estructuras institucionales y de las relaciones de autoridad". Sus investigaciones se limitan a lo que ahora llama socialidad "modesta" ("agencia compartida intencional de pequeña escala en las que están ausentes relaciones asimétricas de autoridad"78). Esto deja deliberadamente lugar para desarrollos en la dirección de las instituciones y la autoridad ${ }^{79}$. Y, por otro lado, es cierto que gran parte del esfuerzo de Shapiro está dedicado precisamente a esa tarea.

En ausencia de un tratamiento explícito y sustancial de estas cuestiones por parte de Bratman, no nos queda más que imaginar qué forma habría dado Bratman a sus ideas, con relación a la actividad compartida en contextos institucionales (i.e., donde están en pie "estructuras institucionales y relaciones de autoridad") ${ }^{80}$. Esto claramente no es un argumento. En defensa de mis objeciones puedo solo decir que no creo que los agregados propuestos por Shapiro vayan en la dirección correcta, precisamente por las razones indicadas en la sección precedente (véase también infra, en esta sección, sub [2]). En la teoría de Shapiro, las tesis relevantes (normas jurídicas como planes, la actividad legal como actividad de planificación) son defendidas al

77 Bratman, M. E., Faces of Intention. Selected Essays on Intention and Agency, op. cit., p. 94 y 142; Bratman, M. E., "Shapiro on Legal Positivism and Jointly Intentional Activity", op. cit., p. 512; Bratman, M. E., "Dynamics of Sociality", op. cit.; Bratman, M. E., "Modest Sociality and the Distinctiveness of Intention", op. cit., p. 122.

${ }^{78}$ Bratman, M. E., "Modest Sociality and the Distinctiveness of Intention", op. cit., p. 122.

79 "Reflexionar acerca de la estructura subyacente a la socialidad modesta puede también ayudarnos a pensar casos de mayor escala, tales como el derecho y/o la democracia" (Bratman, M. E., "Modest Sociality and the Distinctiveness of Intention", op. cit., p. 150).

${ }^{80}$ La discusión que Bratman ofrece de las "valoraciones compartidas" (Bratman, M. E., "Dynamics of Sociality", op. cit.; Bratman, M. E., Structures of Agency. Essays, op. cit., cap. 13) parece ser el primer paso en esta dirección (véase especialmente su análisis de la adopción, en un departamento universitario, de una política relativa a la admisión de estudiantes, y su relación con las actitudes de cada miembro individual). En mi 
¿Hay algo que los planes puedan hacer por la teoría del derecho?

precio de diluir demasiado las nociones de plan y de planificación, hasta el punto tal de hacerlas poco informativas ${ }^{81}$.

(2) Aceptación. Al sostener que las normas jurídicas son planes, y que la actividad legal es actividad compartida, Shapiro asume en general que aquellos para quienes se adoptan los planes, ya sean los miembros del Club de la Cocina, las personas trabajando en la compañía Club de la Cocina, los habitantes de la Isla de los Cocineros, los residentes en el Del Boca Vista, o las personas involucradas en el funcionamiento

opinión, en tanto y en cuanto las valoraciones compartidas conlleven también una forma de compromiso por parte de las personas involucradas-compromiso respecto de una cierta política de deliberación (véase esp. Bratman, M. E., "Dynamics of Sociality”, op. cit., p. 3)- las valoraciones compartidas serán un fenómeno completamente diferente del que podría presentar cualquier explicación plausible del concepto, o de la "naturaleza fundamental" del derecho. (Deberíamos, creo, resistir a la tentación de considerar al derecho como una parte esencial del "paquete cerrado" en el que consiste nuestra socialidad, ibidem, p. 4; de otro modo se asumirían demasiadas cosas que deberían ser en realidad probadas). Así, las normas de racionalidad involucradas en las valoraciones compartidas -las exigencias racionales a las que están sujetas- no se aplican, eo ipso, a la "planificación" legal (si bien normas diferentes, que constituyen la "racionalidad interna del prescribir" pueden ser aplicables -véase supra, n. 45-; y pueden existir profundas afinidades entre las primeras y estas últimas).

81 Planificar "en contextos institucionales" se diferencia, sostiene Shapiro, de la planificación "individual", al menos bajo un aspecto crucial: "En contextos institucionales [...] es posible crear un plan aunque quien lo adopta no haya intentado crear una norma"; en el caso de la planificación individual, por el contrario, "el proceso es la actividad psicológica de formarse intenciones" (Shapiro, S. J., Legalidad, op. cit., p. 170). Pero entonces, ¿por qué hablar de "planes" cuando nos referimos al derecho? A menos que la noción relevante de plan sea la noción débil introducida más arriba (n. 52), yo no veo que quede espacio aquí para los planes y las exigencias que los acompañan. No resulta ya correcto decir que "comprender el derecho implica comprender nuestra especial psicología y las normas de racionalidad que regulan su correcto funcionamiento" (ibíd, p. 161; esta era, recuérdese, una de las tesis fundamentales de la teoría del derecho como plan). Además, aun cuando sea cierto que, en contextos institucionales, a diferencia de la planificación personal, "es posible crear un plan aunque quien lo adopta no haya intentado crear una norma" (ibidem, p. 170), resulta de todos modos oscuro de qué modo esto tiene lugar. (Las teorías del derecho de Kelsen y Olivecrona también enfrentan esta dificultad; por ejemplo, cuando se refieren a las normas jurídicas como "órdenes despsicologizadas", o como "órdenes impersonales y anónimas", véase Kelsen, H., General Theory of Law and State, Cambridge (Mass.), Harvard University Press, 1945, pp. 35-36.) Un esbozo de explicación puede encontrarse en Shapiro, S. J., Legalidad, op. cit., p. 263: "La introducción de la normatividad 


\section{de un sistema jurídico, aceptan los planes que los otros hacen y adoptan para ellos (nótese que ello también es cierto con relación a ACM) ${ }^{82}$. Esto, por supuesto, evitaría la mayoría de mis objeciones. Si asumimos que todos los individuos involucrados aceptan los planes relevantes, y}

institucional es un avance revolucionario en la planificación social. Es posible adoptar planes sin que los planificadores pretendan en realidad que la comunidad actúe de conformidad. En consecuencia, la comunidad no necesita preocuparse por si los planificadores tuvieron estas intenciones. Pueden saber que tienen la obligación jurídica simplemente porque los planificadores siguieron los procedimientos correctos. Por supuesto, la institucionalización del derecho está en última instancia basada en las intenciones. Las reglas son jurídicamente válidas porque fueron creadas de conformidad con una regla que la mayoría de los funcionarios aceptan [las cursivas son mías]. Si los funcionarios dejasen de aceptar el plan, entonces los planes creados de acuerdo con él también dejarían de ser jurídicamente válidos". Esto parecería instaurar una continuidad entre la psicología de la planificación individual y la planificación institucional. Una continuidad que parecería rescatar la tesis según la cual la comprensión de la segunda implica la comprensión de la primera, pero esta conexión me resulta de todos modos misteriosa. Respecto de esta cuestión, como también de otros puntos cruciales del argumento de Shapiro, todo el trabajo explicativo y justificatorio necesario es llevado a cabo, de hecho, por una implícita teoría de la legitimidad, basada en la aceptación (véase infra, en esta sección, sub [2]). Y, ¿estamos asumiendo que los funcionarios, todos ellos, poseen las intenciones relevantes? (Recuérdese que supuestamente la actividad legal es una ACM; v. supra, § 5).

82 Véase, por ejemplo, Shapiro, S. J., Legalidad, op. cit., pp. 193-194: "Para que un grupo actúe en conjunto, no es necesario que pretenda tener éxito en la empresa conjunta. Solo necesita compartir un plan. Ese plan, a su vez, puede ser desarrollado por quien pretende el éxito de la actividad conjunta. En la medida en que los participantes acepten el plan, cumplan intencionalmente con su parte y resuelvan sus problemas pacífica y abiertamente, y todo esto sea de conocimiento común, están actuando en conjunto de manera intencional". Parte del material relevante ha sido citado más arriba, en la n. 39. Véase también ibidem, p. 230 y la sección del capítulo 6, "La racionalidad interna del derecho". Aquí, las normas de la racionalidad instrumental ("las normas distintivas de la racionalidad que asisten a la actividad de planificar", ibid., p. 231: consistencia, coherencia, la no reconsideración del plan en ausencia de razones perentorias) se aplican solo a quienes acepten las normas jurídicas fundamentales (i. e., el plan maestro). Es decir, se aplican solo a los funcionarios y a los "buenos" ciudadanos. (Las normas relevantes de racionalidad gobiernan la actividad de planificación; así, se aplican únicamente a quienes están comprometidos con el plan). Los bad men no están sujetos a sus exigencias. ("La racionalidad interna del derecho es un conjunto acotado de restricciones, porque las normas de la planificación solo se aplican a quienes aceptan planes. Por lo tanto, el hombre malo no puede ser criticado racionalmente por no obedecer a las autoridades jurídicas en tanto no acepta el derecho", ibidem, p. 231). 
¿Hay algo que los planes puedan hacer por la teoría del derecho?

los hacen propios tal como si los hubieran diseñado y adoptados ellos mismos, entonces hablar de autoridad de los planificadores se vuelve ciertamente apropiado. $\mathrm{O}$, en todo caso, se hace verdadero por hipótesis que la actividad bajo análisis es una actividad compartida. Pero este modo de formular las tesis en cuestión (que las normas jurídicas son planes, que la actividad legal es actividad de planificación, y que las normas jurídicas poseen, en cuanto tales, fuerza vinculante, no basada en su legitimidad moral) las hace trivialmente verdaderas y las priva de todo poder informativo o explicativo relevante. Esta estrategia -asumir que todas las partes involucradas aceptan los planes relevantes- no arroja ninguna luz en situaciones menos irénicas. Primero, en el caso del derecho la asunción es problemática. No deberíamos hacer una cuestión de necesidad conceptual, o de la "naturaleza fundamental" del derecho, que todas las personas sujetas a las normas jurídicas las $\operatorname{aceptan}^{83}$. Y, segundo, el trabajo teórico necesario es llevado a cabo aquí por una teoría del consenso implícita. Se trata de una teoría normativa, sustancial (si bien no necesariamente moral) de la legitimación mediante aceptación ${ }^{84}$. En pocas palabras, si asumimos que los indivi-

${ }^{83}$ Quizás las tesis de Shapiro (las normas jurídicas son planes, etc.) se refieren solo a los funcionarios, y no pretenden incluir todos los individuos involucrados en el funcionamiento del sistema jurídico. (Me resulta difícil determinar si, en el texto de Shapiro, "participantes" en un sistema jurídico comprende solo a los funcionarios, o a todos los miembros del grupo social relevante). Pero, incluso si adoptamos esta lectura (que no encaja del todo bien con muchas de las cosas que escribe Shapiro, véase, por ejemplo, ibidem, p. 215), resulta igualmente dudosa la tesis según la cual la actividad legal es actividad de planificación compartida, en tanto descanse en la asunción de que todas las partes involucradas aceptan el plan relevante. Si asumimos que (siempre y en todo lugar) es cierto que todos los funcionarios aceptan los "planes" legales -concibiendo a los funcionarios como un grupo unificado, en el que todos están de acuerdo en aceptar los "planes" legales-, y consideramos esta asunción como una base suficiente para concluir que la actividad legal es actividad compartida; entonces esta última conclusión resulta, desde mi punto de vista, poco informativa.

${ }^{84}$ Véase, por ejemplo, Shapiro, S. J., Legalidad, op. cit., p. 193: "Como hemos visto, respondemos al desafio de dirigir a un grupo numeroso de individuos sin experiencia ni motivación exigiéndoles que nos cedan en gran medida la potestad de planificar. Al aceptar el plan compartido, no solo asumen ciertas funciones, sino que transfieren su potestad de adoptar y aplicar planes cuando ellos entran en conflicto con los planes de los supervisores". La "Transferencia de potestad de planificar" a través de la aceptación, 


\section{duos relevantes se someten o se comprometen ellos mismos a cumplir con el derecho, entonces no debería sorprendernos verificar que se encuentran sometidos o comprometidos ${ }^{85}$.}

o el consentimiento, posee claramente aroma contractualista. ¿Las tesis de Shapiro (normas jurídicas como planes, actividad legal como actividad compartida) descansan entonces en premisas normativas implícitas, de corte contractualista o cuasicontractualista? Algunos fragmentos de una teoría sustantiva y normativa de la legitimidad pueden recabarse en el texto de Shapiro. Considérese por ejemplo el principio siguiente (ibidem, p. 186): "el hecho de que alguien adopte un plan para que otros lo sigan no significa que, desde el punto de vista moral, ellos deban obedecer. El plan puede ser insensato o malvado, por tanto, salvo que haya costes sustanciales asociados al incumplimiento, los sujetos deberían moralmente abstenerse de llevarlos adelante. Sin embargo, si el sujeto ha aceptado el plan compartido que establece la jerarquía, entonces, desde el punto de vista de la racionalidad instrumental, está obligado a prestar atención al plan. Si alguien accediese a la planificación de otra persona y luego ignorase una orden dirigida a él, estaría actuando de manera inconsistente con su propio plan [las cursivas son mías]. Su desobediencia estaría en conflicto frontal con su intención de deferir".

85 A veces, sin embargo, Shapiro argumenta de manera diferente. En la Isla de los Coniceros, "el plan que establece la jerarquía para la isla es un plan compartido" (Shapiro, S. J., Legalidad, op. cit., p. 211). Shapiro continúa diciendo (ibidem, pp. 211-212): "Adviértase también que, como el plan compartido fue diseñado para unos pocos planificadores sociales, son ellos quienes comparten el plan, no los isleños en conjunto. Esto significa que no es necesario que la comunidad acepte el plan compartido para que este tenga lugar [las cursivas son mías] -aunque, de hecho, nosotros aprobamos el plan-. Al considerar que los planificadores sociales tienen legitimidad moral, nuestro plan es permitir que quienes adoptan y aplican planes lo hagan para nosotros. Por esta razón, consideramos que el plan compartido es el 'plan maestro' para nuestro grupo". (Véase también ibid., p. 194, sobre ACM, ibidem, p. 224, y supra, sobre el bad man, n. 82). Por supuesto, esto no encaja bien con los comentarios que he hecho aquí. Pero tampoco logro ver cómo ello encaja con los argumentos de Shapiro. No me resulta del todo claro qué es lo que significa el "tenga lugar" escrito en cursivas. Específicamente, ¿los habitantes que no han aceptado el plan se encuentran de todos modos sujetos a la presión de las normas de racionalidad instrumental que se aplican a los planificadores? Si la respuesta es no, entonces, ¿en qué sentido las normas jurídicas son planes compartidos? ¿En qué sentido la actividad legal es actividad de planificación? (Recuérdese la "tesis de la planificación", ibidem, pp. 200-201: "las instituciones jurídicas planifican para las comunidades sobre las que pretenden tener autoridad, tanto diciendo a sus miembros que pueden, o no pueden, hacer, como identificando quiénes tienen derecho a afectar lo que otros pueden o no hacer. Siguiendo esta idea, las reglas jurídicas son ellas mismas planes generalizados, o normas similares a los planes, emitidas por quienes están autorizados a planificar para otros. Y la decisión judicial supone la aplicación de estos planes, o normas similares a los planes, a quienes les son aplicables"). Y no logro ver cómo la respuesta pueda ser, en algún sentido plausible, 
¿Hay algo que los planes puedan hacer por la teoría del derecho?

(3) Coerción. Bratman ${ }^{86}$ sostiene que puede haber intención compartida y ACI (si bien no una ACC) incluso en presencia de coerción o de "fuerte negociación". Estas son buenas noticias para la teoría del derecho como plan. Parece que ahora es posible liberar a la tesis según la cual las normas jurídicas son planes, y la actividad legal es actividad compartida, de la sospecha de descansar en una mirada irénica de las actitudes de los funcionarios o de los sujetos jurídicos en general. Por supuesto, la actividad legal se apoya en la aceptación del derecho por parte de todos los involucrados (véase supra, en esta sección, sub [2]), pero esto no debería preocuparnos, puesto que también la aceptación bajo coerción sería suficiente. Y, se dirá, cada vez que un sistema jurídico existe -cada vez que no está teniendo lugar una revolución o una guerra civil- existirá al menos aceptación bajo coerción.

Shapiro efectivamente explota esta línea argumentativa. En ACM y, por lo tanto, en la actividad legal, la aceptación de la jerarquía, y la "transferencia de poder de planificación" a los superiores que ella conlleva (y que supuestamente funda la aplicación de las normas relevantes de racionalidad instrumental a aquellos para quienes se adoptan los planes; véase supra, en esta sección, sub [2]) puede ser el resultado de la coerción ${ }^{87}$.

sí. Una vez más (supra, §3), ¿por qué diantres el plan que tú creaste o adoptaste para mí debería eo ipso ponerme bajo una "presión racional para actuar en consecuencia" (ibidem, p. 169)?

${ }^{86}$ Bratman, M. E., Faces of Intention. Selected Essays on Intention and Agency, op. cit., pp. 101-102, 122, 132; Bratman, M. E., "Modest Sociality and the Distinctiveness of Intention", op. cit., p. 123.

87 "Tampoco debería pasarse por alto que los individuos podrían aceptar una función subordinada en una actividad compartida porque carecen de otras alternativas viables. Podrían necesitar el dinero desesperadamente o temer el sufrimiento de un daño si no lo hacen. Incluso en casos de coerción económica o física, una vez que los individuos forman la intención de otorgar a las directivas de sus superiores más peso que a los propios planes, han transformado su situación normativa y están racionalmente -no moralmente- comprometidos a seguirlas a menos que aparezcan de repente nuevas razones que los fuercen a reconsiderar" (Shapiro, S. J., Legalidad, op. cit., p. 187). Véase también ibidem, pp. 227-228. Si los miembros de la comunidad no están dispuestos a observar los planes legales (téngase en cuenta que la existencia de esa disposición es, en la teoría de Shapiro, una condición necesaria para la existencia de un plan) 
Confieso que no poseo un verdadero argumento contra esta estrategia. Me parece simplemente demasiado fácil conservar la actividad compartida al precio de diluir las nociones de agencia compartida y de planificación. De nuevo, si asumimos que, siempre y en todo lugar, hay aceptación y que, por lo tanto, los "planes" adoptados para otros son sus propios planes (de manera tal que las normas relevantes son aplicables a ellos), la teoría de los planes será trivialmente verdadera, y no poseerá ningún poder informativo o explicativo significante.

(4) Alternativas a un fundamento pragmático de la planificación. Como hemos visto, la teoría de los planes debe mucho a la tesis de Bratman según la cual la planificación posee un fundamento pragmático. Los planes son instrumentos multiuso, de manera análoga a los bienes primarios de Rawls. La tesis que los planes -y, por lo tanto, el derecho- están sujetos al gobierno de normas de racionalidad instrumental puede, en última instancia, ser rastreada hasta esta idea fundamental.

En escritos recientes, Bratman ha desarrollado, junto a una justificación instrumental de la planificación, un fundamento ulterior, diferente, que tiene que ver con nuestra búsqueda de autogobierno y autonomía ${ }^{88}$ (i.e., con las "conexiones entre la planificación y el autogobierno" 89 ).

¿Se aplica esto a la "planificación" legal? No, creo yo; a menos que, una vez más, entendamos que la autoridad del derecho es análoga

"las autoridades jurídicas pueden disponerlos a cumplir mediante distintas formas de intimidación" (este punto se repite en pp. 227 y 252-253).

${ }^{88} \mathrm{Al}$ igual que con el papel de la planificación en aquellas formas de socialidad a las que atribuimos gran importancia (sobre esto, véase supra, $\S 5$, y en esta sección, sub ([1]). Véase, por ejemplo, Bratman, M. E., "Intention, Belief, Practical, Theoretical", op. cit., p. 36, y n. 74 ("las estructuras de planificación intertemporal e interpersonal son, en parte, constitutivas de [...] formas de integridad intertemporal y de formas de autogobierno y socialidad intertemporales que consideramos altamente valiosos"); Bratman, M. E., "Intention, Practical Rationality, and Self-Governance", op. cit., p. 412 , esp. n. 2 ("para agentes planificadores como nosotros, nuestra razón para cumplir con las normas de la racionalidad práctica deriva en parte de nuestra razón para gobernar nuestras propias vidas"), cap. 5, nn. 7-13, p. 176-180; cap. 8, nn. 35-44, p. 312-315; cap. 11, nn. 8-25, pp. 381-385. Shapiro hace una referencia indirecta a estos desarrollos en la n. 4 del cap. 5. 
¿Hay algo que los planes puedan hacer por la teoría del derecho?

o idéntica a (i.e., un caso particular de) la autoridad que un agente posee sobre sus propias acciones y deliberación (esto es, a menos que concibamos, una vez más, a la totalidad de los agentes jurídicos, o de funcionarios, como un cuerpo unificado que persigue una meta bien definida y converge en la aceptación de los "planes" legales; véase supra, en esta sección, sub [2]). Lo que me deja perplejo, en estas afirmaciones recientes de Bratman acerca de las razones que los humanos poseen para planificar, es que se apoyan en las capacidades que los planes, y las intenciones, proveen a los agentes para el auto-gobierno. Y esto, como he sostenido (supra, § 3) es precisamente lo que impide cualquier analogía plausible con la "planificación" legal ${ }^{90}$.

(5) La fuerza excluyente de los planes (algunas observaciones poco concluyentes). La adopción de un plan es un modo para definir un curso de acción. Los planes, las intenciones y, en general, las actitudes similares a planes no entran en el balance de razones a favor o en contra de un

${ }^{90}$ Parte de la justificación más reciente y compleja de la agencia planificadora, ofrecida por Bratman, según la cual es constitutiva de formas de integridad y auto-gobierno, se relaciona explícita y directamente con la autoridad que los planificadores poseen sobre sus propias acciones y deliberaciones (específicamente, con las actitudes que poseen autoridad agencial; véase, por ejemplo, Bratman, M. E., "Intention, Belief, Practical, Theoretical", op. cit., p. 38: "esta cuestión [qué significa que un pensamiento o una actitud habla por el agente, que significa que posee autoridad agencial] está implícita en varias de las razones relativas a la agencia planificadora que he esbozado. He asumido que nuestra respuesta a la pregunta ¿por qué ser un agente planificador? apelará a estructuras relativas a la integridad intertemporal y a la autonomía. Y, en ambos casos, estas estructuras involucran la guía mediante actitudes básicas que hablan por el agente, que poseen autoridad agencial. He también asumido que nuestra respuesta a la pregunta ¿por qué ser un agente planificador? apelará al papel de la agencia planificadora en la agencia efectiva en general - efectiva en el sentido de defender los valores, intereses, metas y propósitos que constituyen el punto de vista práctico del agente. Y la pregunta, ¿qué es lo que constituye el punto de vista práctico del agente?, es una cuestión relativa a la autoridad agencial"). Es interesante notar que aquí, la línea argumentativa de Bratman va de las condiciones para el autogobierno y la autoridad agencial a la relevancia de la planificación. No se trata únicamente de que la planificación presupone la autoridad de los planificadores (tal como he asumido hasta ahora, supra $\$ \S 2-3$ ). También, al revés, es nuestro interés en la autoridad agencial que nos conduce a (i.e., justifica) la planificación. (Véase también ibidem, p. 39). Esto, creo, refuerza la conexión entre la planificación y la autoridad sobre la que me he apoyado desde el principio y que, he sostenido, no se verifica en el caso de la "planificación" legal. 
determinado curso de acción (esto sería tanto demasiado débil como demasiado fuerte, y produciría una circularidad inadmisible). Por el contrario, proveen lo que Bratman llama "esquema de razones" y dan lugar a problemas relativos a los medios, los pasos preliminares, la elección de opciones relevantes, el descarte de opciones inconsistentes ${ }^{91}$. Los planes, dice Shapiro, "han de excluir", y pretenden ofrecer razones para excluir ${ }^{92}$, la deliberación sobre el balance de razones y estructuran la deliberación sucesiva acerca de cómo llevarlos a cabo. Y esto también es así en la teoría del derecho como plan, puesto que las normas jurídicas son planes ${ }^{93}$.

Todo esto parece acercarse bastante a la idea de que los planes, y las normas en general, son (si válidos) razones excluyentes ${ }^{94}$. Los planes bratmanianos, sin embargo, no son razones excluyentes (o protegidas) à la $\mathrm{Raz}^{95}$. Y esto es así bajo al menos dos aspectos: (a) las normas que determinan la razonable estabilidad de los planes dan de todos modos espacio a la posibilidad de reconsideración, mientras que las razones excluyentes no lo hacen. (b) El modo en que las intenciones, los planes y demás estructuran el razonamiento práctico -es decir, como esquema de razones- es diferente al modo en que lo hacen las razones excluyentes. Sería interesante investigar estas diferencias.

91 Bratman, M. E., Intention, Plans, and Practical Reason, op. cit.

${ }^{22}$ Shapiro, S. J., Legalidad, op. cit., pp. 169-171.

${ }^{93}$ Véase, por ejemplo, p. 252 ("las instituciones jurídicas no se encargan de hacer recomendaciones o peticiones. No presentan sus reglas como un factor más que los sujetos habrían de considerar al decidir qué deberían hacer. Más bien, su tarea es resolver las cuestiones normativas en su favor y reivindican el derecho de exigir el cumplimiento. Por esta razón, la deliberación o la negociación con los funcionarios respecto de si corresponde la obediencia normalmente expresa una profunda falta de respeto hacia ellos y la autoridad del derecho. Más allá de que los cinturones de seguridad sean una buena idea, se exige a los pasajeros que los utilicen - después de todo, es el derecho"); ibidem, p. 337 ("Las normas guían la conducta del mismo modo en que lo hacen los planes, a saber, suprimiendo la deliberación y orientando al sujeto a actuar de acuerdo con el plan").

94 Raz, J., Practical Reason and Norms, London, Hutchinson, 1975; Raz, J., "Reasons for Action, Decisions, and Norms" (1975), en Raz, J. (ed.), Practical Reasoning, Oxford, Oxford University Press, 1978.

95 Bratman, M. E., Intention, Plans, and Practical Reason, op. cit., p. 178 y 180; Bratman, M. E., Structures of Agency. Essays, op. cit., p. 290. 
¿Hay algo que los planes puedan hacer por la teoría del derecho?

Según Shapiro, las normas jurídicas, al igual que los planes -los planes ordinarios, de cada día- son derrotables. Un rasgo peculiar de las normas jurídicas, en comparación con los planes de todos los días, es, sin embargo, que el derecho en sí mismo especifica las condiciones bajo las cuales han de revisarse las normas jurídicas o ha de bloquearse su aplicación ${ }^{96}$. Las normas jurídicas especifican sus propias condiciones de derrotabilidad ${ }^{97}$.

Ahora bien, las normas jurídicas son, según Shapiro, planes, o normas similares a planes. Pero, podríamos preguntar, ¿pueden los planes especificar de manera no vacía las condiciones de su propia revisión o abandono? La pregunta tiene dos caras. (a) ¿Es conceptualmente posible que una norma especifique anticipadamente, en términos no vacíos ni triviales (e.g., "a menos que haya razones perentorias en contrario"), sus propias condiciones de derrotabilidad? (b) ¿Pueden los planes (en el sentido estricto de Bratman) especificar anticipadamente las condiciones bajo las cuales han de ser revisados o abandonados?

En otro lugar ${ }^{98}$ he argumentado que tratar las normas como algo que puede especificar anticipadamente, de manera no vacía ni trivial, sus propias condiciones de derrotabilidad es -dejando de lado contextos especiales- eminentemente irrazonable. (Por supuesto, esto no es un argumento). La última pregunta puede, también, poseer aquí consecuencias significativas. Puesto que, si descubriéramos que un plan, propiamente dicho, no puede, en cuanto tal, satisfacer esta condición, y

96 Véase Shapiro, S. J., Legalidad, op. cit., pp. 252-253 ("Que el derecho haya de resolver, y pretenda resolver, cuestiones normativas no debe interpretarse como que el derecho exige que sus prescripciones sean obedecidas pase lo que pase. Como todos los planes, las leyes son típicamente derrotables. Cuando existen razones de peso, el derecho nos permitirá en general reconsiderar sus prescripciones y deliberar sobre los méritos. La cuestión es que el derecho pretende la prerrogativa de determinar las condiciones de su propia derrotabilidad. Intenta determinar cuándo los problemas que ha solucionado se vuelven inestables"); ibidem, p. 368 ("el derecho [...]) regula el modo de su propia derrotabilidad: identifica las clases de razones que suspenden las exigencias jurídicas”).

${ }^{97}$ Hablar de una única norma que hace ese trabajo, o de normas adicionales que especifican las condiciones de derrotabilidad de cierta norma, no produce ninguna diferencia relevante, creo.

98 Celano, B., True Exceptions: Defeasibility and Particularism, op. cit. 
concediéramos a Shapiro que una norma jurídica sí la satisface, la tesis de Shapiro según la cual las normas jurídicas son planes, o similares a los planes, se encontraría desafiada. Shapiro no podría consistentemente afirmar al mismo tiempo que las normas jurídicas son planes, o similares a los planes, y que especifican sus propias condiciones de derrotabilidad. Y, en mi opinión, la idea de que los planes pueden, de manera no vacía, especificar anticipadamente sus propias condiciones de derrotabilidad es bastante ajena a la teoría de Bratman. (Si bien esto tampoco es un argumento).

\section{Conclusión}

Quizás Shapiro vería todo esto como la consecuencia de una serie de incomprensiones. Quizás Shapiro quería solamente afirmar que las normas jurídicas son típicamente "parcial[es], compuesta[s] y anidada[s]", y que usualmente son "creada[s] por un [...] proceso, $[. .$. incremental, intencional y que dispone a los destinatarios a cumplir con las normas creadas"99, y rechazaría toda analogía impropia entre la planificación en primera persona y la planificación para otros. Si ello es así, entonces no estamos en desacuerdo. Lo que antecede debería entonces ser entendido como previniéndonos sobre ciertas implicaciones potencialmente engañosas de algunos pasajes cruciales del libro de Shapiro. De todos modos, agregaría que si se descarta la analogía, entonces hablar de normas jurídicas como planes resulta poco informativo. La fuerza principal de la teoría de los planes de Bratman reside en su capacidad para arrojar luz sobre la autoridad que los agentes planificadores (agentes individuales o grupos de ellos) pueden tener sobre ellos mismos, sobre sus acciones y sobre su deliberación. Y es precisamente llegados a este punto que nos vemos compelidos a reconocer, creo yo, que hablar de planes no tiene mucho para ofrecer a la teoría del derecho. 
¿Hay algo que los planes puedan hacer por la teoría del derecho?

\section{Bibliografía}

Benditt, T. M., "Acting in Concert or Going It Alone: Game Theory and the Law", Law and Philosophy, 23 (6), 2004, pp. 615-630.

Bratman, M. E., Intention, Plans, and Practical Reason, Cambridge (Mass.), Harvard University Press, 1987.

Bratman, M. E., Faces of Intention. Selected Essays on Intention and Agency, Cambridge, Cambridge University Press, 1999.

Bratman, M. E., "Shapiro on Legal Positivism and Jointly Intentional Activity", Legal Theory, 8, 2002, pp. 511-517.

Bratman, M. E., "Dynamics of Sociality", Midwest Studies in Philosophy, 30, 1, 2006, pp. 1-15.

Bratman, M. E., Structures of Agency. Essays, Oxford, Oxford University Press, 2007.

Bratman, M. E., "Intention, Practical Rationality, and SelfGovernance", Ethics, 119, 2009, pp. 411-443.

Bratman, M. E., "Modest Sociality and the Distinctiveness of Intention", Philosophical Studies, 144, 2009, pp. 149-165.

Bratman, M. E., "Intention, Belief, Practical, Theoretical", en Robertson, S. (ed.), Spheres of Reason, Oxford, Oxford University Press, 2009, pp. 29-62.

Celano, B., Dover essere e intenzionalità. Una critica all'ultimo Kelsen, Torino, Giappichelli, 1990.

Celano, B., "Validity as Disquotation", en Comanducci, P. y Guastini, R. (eds.), Analisi e diritto 1999. Ricerche di giurisprudenza analitica, Torino, Giappichelli, 2000, pp. 35-77.

Celano, B., "La regola di riconoscimento è una convenzione?", en Redondo, M. C. (ed.), "Il "Postscript" di H. L. A. Hart", Ragion pratica, 21, 2003, pp. 347-360.

Celano, B., "True Exceptions: Defeasibility and Particularism", en Ferrer Beltrán, J. y Ratti, G.B. (eds.), The Logic of Legal Requirements: Essays on Defeasibility, Oxford, Oxford University Press, 2012, pp. 268-287. 
Coleman, J. L., The Practice of Principle. In Defense of a Pragmatist Approach to Legal Theory, Oxford, Oxford University Press, 2001.

Gaus, G. F., "The Legal Coordination Game", American Philosophical Association Newsletter on Philosophy and Law, 1, 2002, pp. 122-128.

Kelsen, H., General Theory of Law and State, Cambridge (Mass.), Harvard University Press, 1945.

Raz, J., Practical Reason and Norms, London, Hutchinson, 1975.

Raz, J., "Reasons for Action, Decisions, and Norms" (1975), in Raz, J. (ed.), Practical Reasoning, Oxford, Oxford University Press, 1978.

Shapiro, S. J., "Law, Plans, and Practical Reason", Legal Theory, 8 (4), 2002, pp. 387-441.

Shapiro, S., Legalidad, Madrid-Barcelona, Marcial Pons, 2014, traducción de Papayannis, D. M. y Ramírez Ludeña, L.

Waldron, J., Law and Disagreement, Oxford, Oxford University Press, 1999. 